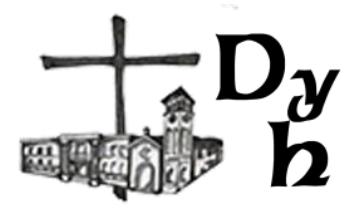

El esse y el bien en el comentario al De divinis nominibus del Pseudo Dionisio Areopagita

Alain Contat

Dios y el hombre, vol. 5, n. 1, e079, 2021

ISSN 2618-2858 - https://doi.org/10.24215/26182858e079

https://revistas.unlp.edu.ar/DyH/index

Cátedra libre de pensamiento cristiano - UNLP

Seminario Mayor San José

La Plata, Buenos Aires, Argentina

\title{
EL ESSE Y EL BIEN \\ EN EL COMENTARIO AL DE DIVINIS NOMINIBUS DEL PSEUDO DINOSIO AREOPAGITA
}

\author{
EsSe and Good \\ in the Commentary on Pseudo-Dionysius's De Divinis Nominibus
}

\author{
Alain Contat \\ alain.contat@wanadoo.fr \\ Ateneo Pontificio Regina Apostolorum - Roma - Italia
}

\begin{abstract}
Traducción de Contat, A: L'esse et le bien dans le commentaire sur le De divinis nominibus du Pseudo-Denys Aréopagite. «Revue thomiste», 120 (2020), p. 25-58.

\section{Resumen}

Desde hace más de medio siglo, los amigos de santo Tomás de Aquino se han interesado en la influencia que el tratado sobre Los nombres divinos ha ejercido en su metafísica. En este camino, nos detendremos aquí sobre las relaciones recíprocas entre el bien y el ser (esse) en el comentario del Doctor angélico. Esperamos haber puesto más claramente en evidencia las dos líneas directrices que gobiernan, en este punto, la recepción del Pseudo Dionisio en el pensamiento del Aquinate: una fuerte divergencia, que conduce a este último a invertir la primacía dionisiana del bien sobre el ser; y una no menos fuerte convergencia, que desemboca en la noción de esse intensivo, fuente de toda la perfección del ente.
\end{abstract}

Palabras clave: ser, esse, bien, Pseudo Dionisio, Tomás de Aquino.

\section{Abstract}

For more than a half century, the friends of St. Thomas Aquinas have been interested in the influence which the treatise On the divine names has had on metaphysics. Following this trail, we would like to tarry here on the reciprocal link between good and being (esse) in the commentary of the Angelic Doctor. We hope to have clearly shown the two lines of direction which command, on this point, the reception of Pseudo-Dionysius in the thought of Aquinas: a strong divergence, which leads the latter to reverse the Dionysian primacy of good over being; and a no less strong convergence, which leads to the notion of intensive esse, source of all the perfection of being.

Keywords: being, esse, good, Pseudo-Dionysius, Thomas Aquinas.

\section{Advertencias para el lector}

1. Las citas que son traducción de otra lengua en el original (por ejemplo, las de Balthasar) se traducen desde el francés, poniendo a pie de página la traducción francesa volcada por el autor.

2. Las citas en latín se traducen a partir del latín, dejando a pie de página el original, tal como lo hace el autor en su artículo.

3. Las citas que son de autores franceses se traducen directamente sin volcar el original a pie de página.

4. Todas las notas del traductor se numeran con números romanos. 
Ha llegado a ser casi un lugar común en el curso de los últimos decenios afirmar que la metafísica de Tomás de Aquino debe mucho a sus fuentes neoplatónicas, empezando por las dos obras que él comentó, a saber, el Liber de Causis y el De divinis nominibus. Excelentes trabajos han explorado esta vía de investigación, notablemente las monografías de Ignacio Andereggen ${ }^{1}$, de Fran $\mathrm{O}^{\prime}$ Rourke ${ }^{2}$, de Thierry-Dominique Humbrecht ${ }^{3}$, entre otros ${ }^{4}$. En lo que concierne al Pseudo Dionisio, la paradoja es patente y conocida. En efecto, el conjunto de los

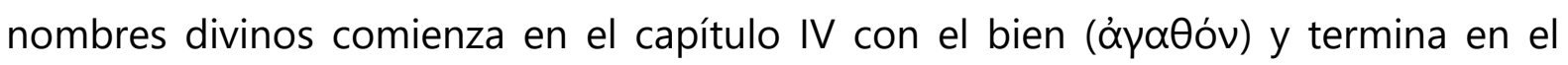
capítulo XIII con lo perfecto (

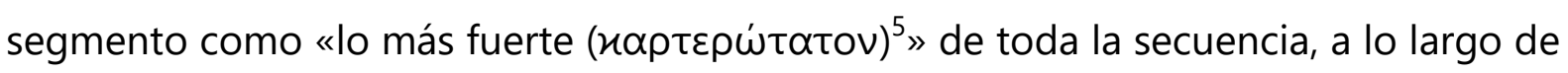
la cual el Areopagita sólo concede al ente (őv) y al ser (عîval) un lugar intermediario en el capítulo $\mathrm{V}$, después de haber desarrollado, a continuación del bien, la luz, lo bello, el amor, el éxtasis y el celo. El Aquinate, al contrario -y como todos saben-, resuelve el bonum en el ens, luego el ens en el esse. La pregunta se pone, por consiguiente, para saber cómo la metafísica tomasiana del ens-esse se refiera a la teología dionisiana del uno-bien: ¿qué le debe y cómo la asume? Aunque este tema no sea nuevo, querríamos ofrecer aquí una contribución -que esperamos que sea útil- a la solución de este problema, deteniéndonos de manera analítica en las

\footnotetext{
${ }^{1}$ Cf. Ignacio Eugenio María Andereggen, La metafísica de santo Tomás en la Exposición sobre el De divinis nominibus de Dionisio Areopagita, Buenos Aires, Editorial de la Universidad Católica Argentina, 1989.

${ }^{2}$ Cf. Fran O'Rourke, Pseudo-Dionysius and the Metaphysics of Aquinas, Notre Dame (IN), University of Notre Dame Press, ${ }^{3} 2010$.

${ }^{3}$ Cf. Thierry-Dominique Humbrecht, Théologie négative et noms divins chez saint Thomas d'Aquin, «Bibliothèque thomiste, 57», Paris, Vrin, 2005.

${ }^{4}$ Cf. Pierre Faucon de Boylesve, Aspects néoplatoniciens de la doctrine de saint Thomas d'Aquin, Paris, H. Champion, 1975 ; Rosa Padellaro de Angelis, L'influenza del pensiero neoplatonico sulla metafisica di S. Tommaso d'Aquino, "Collana di filosofia antica 6», Roma, Edizioni Abete, 1981. A pesar de su erudición, sólo se utilizará con grandes reservas la obra de Klaus Kremer, Die neuplatonische Seinsphilosophie und ihre Wirkung auf Thomas von Aquin, "Studien zur Problemgeschichte der antiken und mittelalterlichen Philosophie, 1», Leiden, Brill, 1966. Este autor, en efecto, identifica el acto de ser con el mismo Ser subsistente, por ejemplo, p. 438: «Das Sein, das alle Formen und Dinge aktuiert, ist daher das ipsum esse subsistens!»

${ }^{5}$ Cf. Pseudo-Denys I'Aréopagite, Les noms divins, XIII, § 1, I. 1-4, 977 B (texto griego de B. R. Suchla y traducción francesa de Ysabel de Andia, "Sources chrétiennes, 579», Paris, Cerf, 2016, p. 166-167: «Maintenant il reste à traiter, s'il te semble bon, le point le plus important. En fait la théologie attribue tous (les noms) et tous ensemble à (Celui qui est) la Cause de tout et le célèbre comme parfait et comme Un» [Ahora, queda tratar, si te parece bien, el punto más importante. De hecho, la teología atribuye todos (los nombres) y todos juntos a (Aquel que es) la Causa de todo y lo celebra como perfecto y como Uno].
} 
relaciones entre el bonum, por un lado, y la dupla ens-esse, por el otro, tal como son tematizadas en el Super librum Dionysii De divinis nominibus. A este fin, ordenaremos nuestra propuesta en tres partes:

1. Después de haber expuesto muy brevemente dos lecturas contemporáneas del orden que gobierna la construcción de Los nombres divinos, presentaremos la de santo Tomás, concentrándonos en sus implicaciones respecto de las prioridades respectivas del bien y del ser.

2. A continuación, examinaremos las relaciones entre el bien y el ens-esse en el cuerpo del comentario, bajo dos puntos capitales: el bien respecto del ente (ens) y del ser (esse); luego, el ser (esse) en sí mismo en tanto que fundamento de todas las otras perfecciones, categoriales o trascendentales.

3. Por último, propondremos una breve conclusión especulativa sobre la «adición» (additio) del bien último al ente substancial y, después, sobre la participación que este mismo bien perfectivo tiene del esse del ente. Mostraremos así cómo santo Tomás asume la herencia dionisiana en su propia metafísica.

\section{El bien y el ser en el ordenamiento de Los nombres divinos}

Para apreciar bien tanto la originalidad cuanto la eventual pertinencia de la economía del tratado pseudodionisiano tal como la reconstruye santo Tomás, será preciso poder compararla a la que un riguroso análisis crítico interno haría aparecer en sí mismo, como es el caso de la Metafísica de Aristóteles. Pero, mientras que la estructura de la «ciencia del ente en cuanto ente» puede fácilmente ser reconstruida en torno a la cuádruple partición de las significaciones de los términos őv-عîval ${ }^{6}$, Los nombres divinos no proporcionan algún criterio explícito de este tipo. El intérprete está, consecuentemente, constreñido a razonar a partir de la serie de predicados que se suceden a lo largo de la obra, de una parte, y de su inspiración evidentemente neoplatónica, de otra parte. En esta perspectiva, un consenso parcial se perfila en

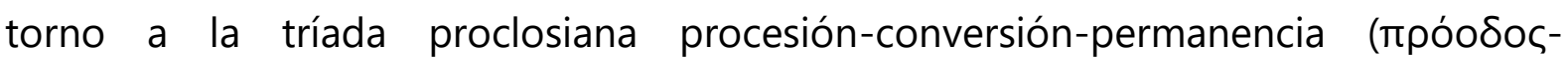

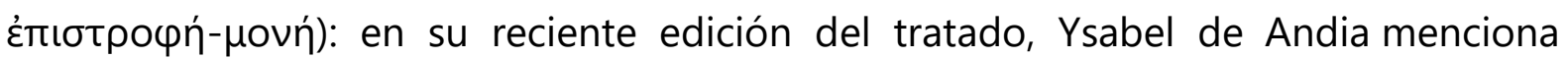

\footnotetext{
${ }^{6}$ Ésta es notablemente la tesis de Giovanni Reale, en Aristotele, Metafisica, 1. Saggio introduttivo e indici, a cura di G. Reale, «Temi metafisici e problemi del pensiero antico, 23», Milano, Vita e Pensiero, ${ }^{2} 1995$, p. 88-106.
} 
tres posiciones que concuerda en este punto: la de Hans Urs von Balthasar, la de Christian Schäfer y la suya propia ${ }^{7}$. La primera y la tercera son importantes para nuestro propósito, porque sitúan al ente y al ser en relación al bien y al uno.

En el primer capítulo de su tratado, el Pseudo Dionisio establece simultáneamente que Dios es innombrable y nombrable: en sí mismo, «Tearquía superesencial», está por encima de todo nombre; pero, en tanto que principio del universo, recibe todos los nombres que se le pueden atribuir a partir de sus efectos. «Así pues, a la causa de todo que está por encima de todo convendrán a la vez la ausencia de nombre y todos los nombres de los entes» ${ }^{8}$. Pero, si Dios es causa, sólo puede serlo por su bondad: «Por el hecho de ser, el bien en tanto que bien esencial extiende su bondad a todos los entes»" " 9 . Si, pues, Dios sólo puede ser nombrado a partir de la relación que él mismo instituye, en el acto creador, con su creación, la bondad aparece entonces como el primero de sus nombres. Desde esta primacía, Balthasar saca dos consecuencias. La primera es obvia para cualquier lector de Los nombres divinos:

Nosotros vemos [al Pseudo Dionisio] más bien ante todo poner la Bondad (agathotês) por encima del actus essendi, con la justificación de que la Bondad engloba en su dominio no sólo el ser, sino también el no ser (que significa toda suerte de potencialidad subjetiva y objetiva): el acto de ser está, entonces, siempre ya englobado por una determinación, la más original de todas, la Bondad ${ }^{\text {III } 10}$.

${ }^{7}$ Cf. Ysabel de Andia, «Introduction», en Pseudo-Denys l'Aréopagite, Les noms divins I-IV, texto griego de B. R. Suchla e introducción, traducción francesa y notas de Ysabel de Andia, "Sources chrétiennes, 578», Paris, Cerf, 2016, p. 20-30. En lo que concierne a Christian Schäfer, cf. The Philosophy of Dionysius the Areopagite, An Introduction to the Structure and the Content of the Treatise "On the Divine Names», «Philosophia antiqua, 99», Leiden - Boston (MA), 2006, en particular p. 64 y 90.

' «Ainsi donc, à la cause de tout qui est au-dessus de tout conviendront à la fois l'absence de nom et tous les noms des étants».

${ }^{8}$ Pseudo-Denys l'Aréopagite, Les noms divins, I, § 7, I. 1-3, 596 C (trad. Y de Andia, SC 578, p. 350-351):

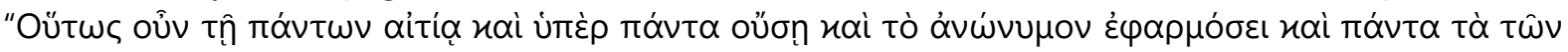

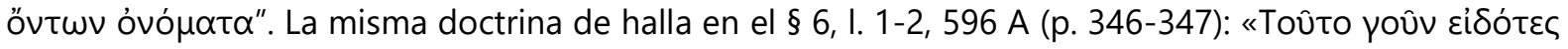

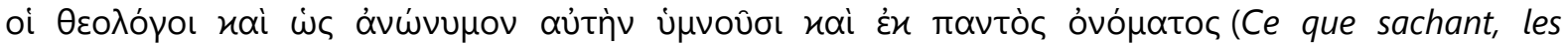
théologiens la célèbrent [= la Théarchie] à la fois comme "sans nom" et "à partir de tout nom")» [Los que saben, los teólogos, la celebran [= la Tearquía] a la vez como "sin nombre" y "desde todo nombre"].

" «Par le fait d'être, le bien en tant que bien essentiel, étant sa bonté à tous les étants».

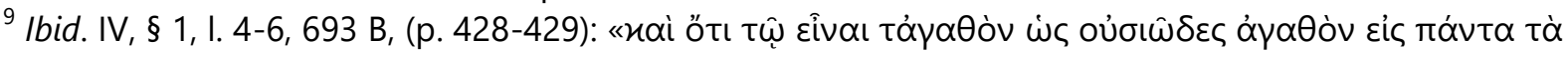

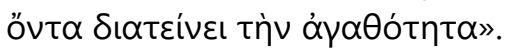

III "Nous [= le Pseudo-Denys] le voyons plutôt d'abord placer la Bonté (agathotês) au-dessus de l'actus essendi, avec cette justification que la Bonté englobe non seulement l'être, mais aussi le non-être (ce 
Así, Dios es visto, en primer lugar, como más allá de toda determinación -lo que indica su trascendencia respecto de la identidad y de la no identidad ${ }^{11}$-; luego, es nombrado e inteligido, en segundo lugar, como bondad, es decir, como principio de difusión fuera de sí y de atracción hacia sí; y solamente en tercer lugar Dios es pensado como ser, es decir, como fuente del ser de los entes. En razón de la doble relación de origen y de fin que ella incluye, la bondad es así el foco del cual emanan los otros nombres.

La segunda consecuencia se sigue inmediatamente de esta tesis. La bondad funda, en efecto, según el teólogo suizo, la sucesión de los nombres divinos según

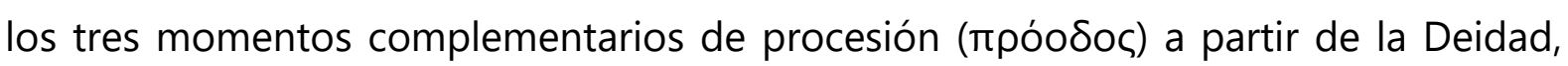

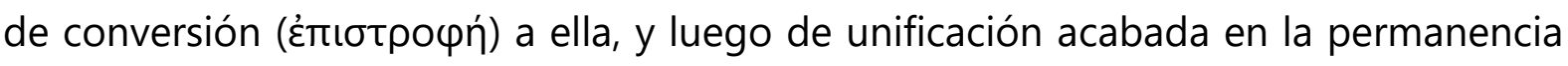

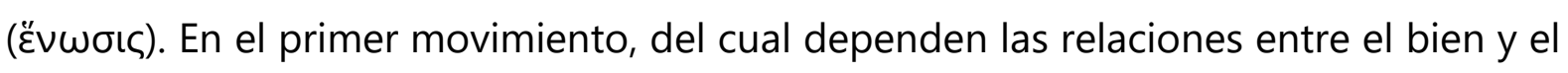
ser, la secuencia sería la siguiente:

Los nombres del acto de creación (nombres de los grados de ser, nombres distributivos, proodos).

$1^{\circ} \mathrm{El}$ nombre de Bien, que engloba todo ser (al lado del cual, del mismo rango y de la misma significación, están los nombres de la Luz, de la Belleza y del Eros. El mal considerado desde el punto de vista del Bien que lo engloba) [cap. 4];

$2^{\circ}$ El acto de ser que funda todos los grados. Lo que es fundamental en el ser, idea, metochê [cap. 5];

$3^{\circ}$ La vida como forma particular (intensidad) del ser [cap. 6];

$4^{\circ}$ el espíritu (nous) como intensidad suprema del ser. $Y$, asimismo, la actividad del espíritu (razón, fe) y la verdad [cap. 7 a] ${ }^{\mathrm{IV} 12}$.

qui signifie toute sorte de potentialité subjective et objective) : l'acte d'être est donc toujours déjà englobé par une détermination, la plus originelle de toutes, la Bonté».

10 Hans Urs von Balthasar, La gloire et la croix, Les aspects esthétiques de la Révélation, II Styles, * D'Irénée à Dante, trad. por Robert Givord et Hélène Bourboulon, «Théologie, 74», Paris, Aubier, 1968, p. 171 (Original alemán: Herrlichkeit. Eine theologische Ästhetik, Bd. II. Fächer der Stile, Teil I. Klerikale Stile, Einsiedeln, Johannes Verlag, ${ }^{3} 1984$, p. 191).

${ }^{11}$ Cf. ibid., p. 172 (texto original, p. 192): «Lui qui crée et fait sortir de lui toute relation et toute opposition dans le monde, est par là nécessairement au-delà de l'identité (tautotês) et de la nonidentité (heterotês), de l'égalité (isotês) et de l'inégalité (amisotês), de la ressemblance (homoiotês) et de la dissemblance (anomoiotês)».

IV «Les noms de l'acte de création (noms des degrés d'être, noms distributifs, proodos).

$1^{\circ}$ le nom du Bien qui englobe tout être (à côté duquel, de même rang et de même signification, il y a les noms de la Lumière, de la Beauté et de l'Éros. Le mal considéré du point de vue du Bien englobant) [ch. 4];

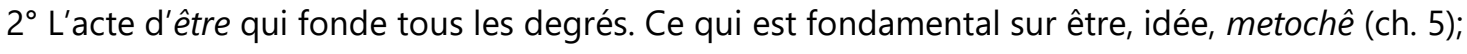

$3^{\circ}$ La vie comme forme particulière (intensité) de l'être (ch. 6); 
En la medida en que las perfecciones puras -la vida, el espíritu, la verdad- sólo son intensificaciones del ser, éste juega una prioridad relativa, pero permanece subordinado al bien, del cual expresa en cierto modo el movimiento de sístole: el ser es un nombre de Dios en tanto que recoge en sí la plenitud de todo lo que, brotando de la bondad divina, puede expandirse fuera de Dios.

Ysabel de Andia contesta esta repartición de los nombres divinos: «No es preciso distinguir tres partes del tratado que correspondan a los tres momentos de la procesión, de la permanencia y de la conversión» ${ }^{13}$. En efecto, el texto mismo del Pseudo Dionisio contradice esta división, que parece por tanto puesta arbitrariamente. Por un lado, por ejemplo, la luz, que Balthasar relaciona con la procesión, está expresamente calificada como efecto de la conversión ${ }^{14}$. Por otro

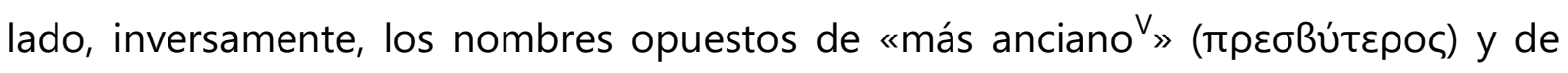

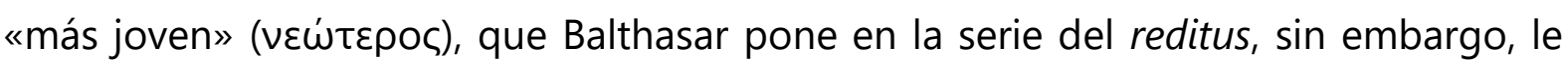
incumben al exitus: «Los dos [nombres] enseñan el hecho de que procede desde el principio, a través de todo, hasta el fin» ${ }^{\mathrm{VI}}{ }^{15}$. Positivamente, la traductora del tratado concibe su unidad del siguiente modo:

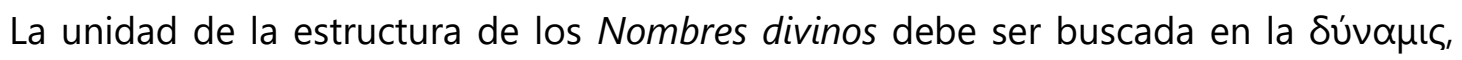
porque la potencia sola permite pensar la unidad de los dos movimientos de procesión y de conversión, y más particularmente esta «potencia unitiva» (vis unitiva) que es el eros [...]. Este «círculo perpetuo» del amor lo conduce de la $\mu$ ovń a la

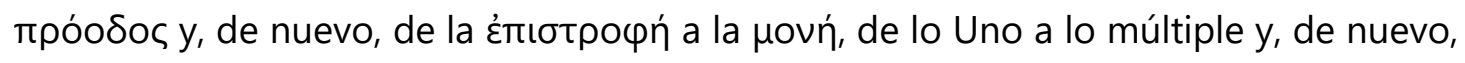
de lo múltiple a lo Uno ${ }^{16}$.

$4^{\circ} L^{\prime} e s p r i t$ (nous) comme intensité suprême de l'être. Et en outre l'activité de l'esprit (raison, foi) et la vérité (ch. 7 a)».

${ }^{12}$ Ibid., p. 173 (texto original, p. 193). Hemos respetado la tipografía de la edición citada.

${ }^{13}$ Y. de Andia, «Introduction»..., p. 25.

${ }^{14}$ Cf. Pseudo-Denys I'Aréopagite, Les noms divins, IV, § 6, I. 12-13, 701 B (SC 578, p. 450-451): «ท่ toû

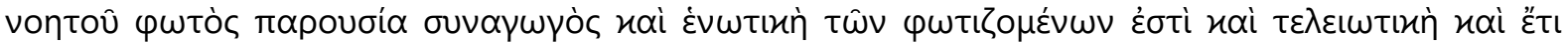

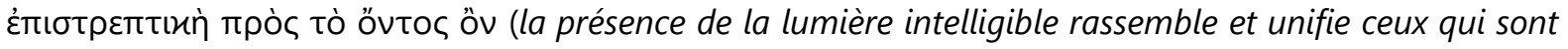
illuminés, les perfectionnant, et, en outre, elle les convertit vers le réellement étant)» [la presencia de la luz inteligible asemeja y unifica a los que son iluminados, perfeccionándolos, y, además, los convierte hacia lo realmente ente].

${ }^{\vee}$ Hemos elegido traducir presbyterós por anciano para poner en evidencia el juego de palabras en griego, donde significa antiguo pero con una alusión a anciano.

$\mathrm{V}^{\prime}$ "Les deux [noms] enseignent le fait qu'il procède depuis le début, à travers tout, jusqu'à la fin».

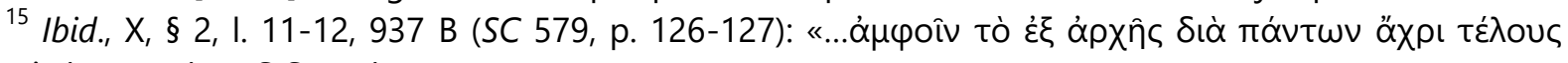

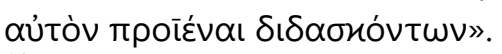

${ }^{16}$ Y. de Andia, «Introduction»..., p. 26-27. 
Puesto que la tríada proclosiana está ahora presente en el centro de cada uno de los nombres divinos, éstos son ordenados de manera menos sistemática que como lo había hecho Balthasar. Y de Andia los reagrupa en dos grandes secciones desiguales: los nombres etiológicos (capítulos IV a XI) y los nombres de la causa en sí misma (capítulos XII y XIII) ${ }^{17}$. Si el cortejo de predicados no va adelante por azar, sino que sigue un itinerario, es porque «el gran movimiento de procesión y de conversión de los nombres divinos comienza con el bien y se acaba con el uno, que es otro nombre del bien, ya que Dionisio dice que el movimiento "va del Bien al Bien por el Bien"» ${ }^{18}$. Aparentemente, esta solución relega el ser más aún que la de Balthasar, ya que lo coloca en la «tríada inteligible», antes que la vida y la sabiduría, entre los nombres del bien y los de la providencia ${ }^{19}$. El motor de la procesión-conversión es el $\varepsilon ̋ \omega \varsigma$, en quien se manifiesta el dinamismo de lo Uno-Bien: en efecto, el amor inclina a la bondad creadora a esta comunicación de bien que es la creación, y también incita a la creatura a retornar a su creador, $y$, entonces, a unirse a aquel que es lo Uno. Pero el हैpwৎ sería atraído en vano por su objeto si no reposara sobre una cierta $\delta u ́ v \alpha \mu \iota \varsigma$, es decir, sobre una cierta «virtud» o potencia activa capaz o de ofrecer el bien amado, o de conquistarlo: de allí la tesis que formula la traductora de Los nombres divinos, en alternativa a la de Balthasar.

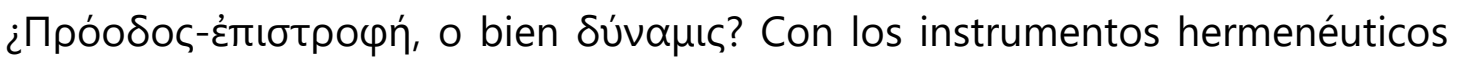
que eran suyos, el Doctor angélico no se inclina en función de esta disyuntiva, sino que elabora una tercera solución que va a poner en primer plano el bien y el ser. Para comprenderla es preciso, ante todo, recordar la arquitectura que él cree poder discernir en la parte propiamente teológica del corpus dionysiacum. En el prooemium, él la divide en cuatro segmentos, que corresponden a cuatro obras de las cuales sólo dos nos han llegado:

1. Los esbozos teológicos (De divinis hypotiposibus, obra ficticia o perdida) habrían tratado de la unidad de la naturaleza divina y de la distinción de las Personas, en tanto que ellas no tienen semejanza suficiente en la creación.

2. Los nombres divinos (De divinis nominibus), a los que conciernen las «semejanzas» que, por así decir, descienden de Dios en la creación; se trata de

\footnotetext{
${ }^{17}$ Cf. ibid., p. 27-29.

${ }^{18}$ Ibid., p. 29. La cita final no es literal, sino que sintetiza Pseudo-Denys l'Aréopagite, Les noms divins, IV, § 17, I. 1-6, 713 D (SC 578, p. 484-485).

${ }^{19}$ Cf. Y. de Andia, «Introduction»..., p. 28.
} 
lo que se llamará más tarde las perfecciones trascendentales, como el bien o el ser, y las perfecciones puras, como la vida o la inteligencia.

3. La teología simbólica (De symbolica theologia, también ficticia o perdida) habría estudiado las metáforas surgidas del mundo sensible, como «león», «roca», «sol».

4. Por último, el opúsculo titulado La teología mística (De mystica theologia) que vuelve a abordar la trascendencia y la incognoscibilidad de la «tiniebla más

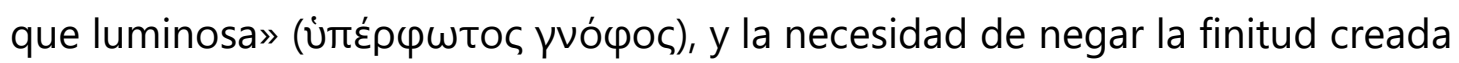
para pensar el misterio de Dios ${ }^{20}$.

La obra teológica del Pseudo Dionisio describiría así una parábola, que partiría del Más allá de todo nombre para volver críticamente al final, después de haber analizado los nombres susceptibles de una atribución propiamente analógica y, después, aquellos que sólo admiten una atribución metafórica.

Dentro de este recorrido, Los nombres divinos exploran los predicados que, por un lado, son de naturaleza puramente inteligible -dado que su noción no incluye la materia-, y, por otro, se hallan de manera participada en las creaturas. Desde el punto de vista del conocer, éstos nos son manifestados en principio en las creaturas, pero, desde el punto de vista del ser, radican primariamente en la unidad absoluta de Dios. Puesto que su significado está así presente en el creador y en las creaturas -salvada la distancia infinita entre éstas y aquél-, estos nombres se atribuyen consiguientemente a Dios en cuanto causa primera. Ahora bien, la bondad da razón de la causalidad creadora; he aquí por qué, según santo Tomás, la teoría dionisiana de los nombres divinos comienza por este atributo:

En efecto, intenta en este libro tratar acerca de los Nombres divinos que manifiestan las procesiones de las creaturas desde Dios, según que Él es Causa de las cosas. Pero, lo que tiene razón de causa, en primer lugar y universalmente es bueno. Esto emerge por una doble razón: la primera, porque lo bueno tiene razón de fin; el fin, además, tiene razón de causa [...]. Segunda, porque el agente obra algo semejante a sí, no en cuanto es ente de cualquier modo, sino en cuanto es perfecto. En efecto, lo perfecto -como se dice en el libro IV de los Meteorológicos- es lo que puede hacer algo símil a

\footnotetext{
${ }^{20}$ Resumimos S. Thomas, In librum beati Dionysii De divinis nominibus expositio (en adelante: In De div. nom.), Prooemium, I (éd. Marietti, p. 1). Cf. también ibid., cap. I, lect. 3 ( $n^{\circ}$ 104): «Cum enim praemissa sint tria genera Dei nominationum, de primo, qui est per remotionem, agitur in Mystica Theologia; de secundo, qui est per intelligibiles processiones, in hoc libro; de tertio, qui est per sensibiles similitudines, in libro de Symbolica Theologia».
} 


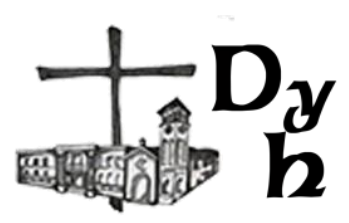

sí mismo. Ahora bien, lo perfecto tiene razón de bien. Así pues, lo que Dios hace a las creaturas, sea el ser, sea el vivir y cualquier otro bien, todo procede de la divina bondad y todo se difunde a la bondad de la creatura ${ }^{21}$.

Pongamos de manifiesto las dos rationes que alega nuestro comentador. La primera se apoya sobre la razón de fin que caracteriza al bien; ahora bien, la causa final es la primera causa precisamente porque da razón de la causalidad de las otras causas $^{22}$; ergo, el bien es lo que hay de primero en el orden de la causalidad. Este argumento se sirve de la descripción del bien como «lo que todos desean». Pero, mientras que la causa segunda -principalmente viviente- puede «desear» un bien que, para ella, está ausente -el deseo, en efecto, mira un bien que el sujeto que desea no posee todavía-, la causa primera, en cambio, no puede asignar a la creación otro fin que ella misma, de tal suerte que su Ser se presupone a su ser-fin, $y$, entonces, a su bondad.

La segunda ratio reposa sobre el axioma según el cual «todo agente obra de manera semejante a sí»; pero, para obrar, es preciso disponer de la actualidad que debe ser participada por el destinatario de la acción, y éste requiere, a su vez, la perfección del agente; ahora bien, lo que es perfecto tiene razón de bien; ergo, todo agente, y ante todo el primer agente que es Dios, tiene razón de bien. Esta demostración resalta la eficiencia del agente -«todo agente obra»-y su ejemplaridad en relación al efecto que causa -«de manera semejante a sí»--. Pero, para ser perfecto al punto de poder comunicar eficaz y ejemplarmente algo de su perfección a otra cosa, es necesario ser. Es por esto que el agente absolutamente perfecto, que es

${ }^{21}$ Ibid., cap. III, lect. un. ( $\mathrm{n}^{\text {os }} 227-228$ ): «Intendit enim in hoc libro agere de divinis Nominibus manifestantibus processiones creaturarum a Deo, secundum quod est Causa rerum. Id autem quod habet rationem causae, primo et universaliter est bonum. Quod apparet duplici ratione: primo quidem, quia bonum habet rationem finis; finis autem, primo, habet rationem causae. Nam forma est causa inquantum facit materiam esse actu; materia autem fit actu primo quando ab agente incipit. Secundo, quia agens agit sibi simile, non inquantum est ens quocumque modo, sed inquantum est perfectum. Perfectum enim ut dicitur in iv Meteorologicorum, est quod potest sibi simile facere. Perfectum autem habet rationem boni. - Sic igitur, quidquid Deus facit creaturis, sive esse sive vivere et quodcumque aliud totum ex bonitate divina procedit et totum ad bonitatem pertinet creaturae» (hemos agregado el contexto).

${ }^{22}$ Cf. S. Thomas, In Metaph., Lib. V, lect. 3 (éd. Marietti, $n^{\circ}$ 782): «Licet finis sit ultimus in esse in quibusdam, in causalitate tamen est prior semper. Unde dicitur causa causarum, quia est causa causalitatis in omnibus causis. Est enim causa causalitatis efficientis, ut iam dictum est. Efficiens autem est causa causalitatis et materiae et formae. Nam facit per suum motum materiam esse susceptivam formae, et formam inesse materiae. Et per consequens etiam finis est causa causalitatis et materiae et formae». 
Dios, debe poseer en plenitud todas las perfecciones que él causa fuera de sí mismo: santo Tomás remarcará esto más adelante, en la lectio de su comentario dedicado a este atributo ${ }^{23}$.

Las dos rationes consideradas juntas dejan así entrever, de manera implícita, la triple causalidad creadora que santo Tomás analiza en la Prima Pars: la eficiencia, que comunica el esse a los entes; la ejemplaridad, que modela sus esencias sobre las ideas divinas correlativas; y la finalidad, que ordena cada uno de los entes, y el universo que ellos constituyen, a su perfección última ${ }^{24}$. En suma, si Dios es triplemente causa del universo en razón de su bondad, eso sólo puede ser sobre el fundamento del Ipsum esse subsistens: la anterioridad que el Pseudo Dionisio concede al bien entra necesariamente en relación, para el Aquinate, con la que no puede no ser reconocida al ser.

Pero, ¿qué hay de la consecución lógica de los nombres divinos posteriores al

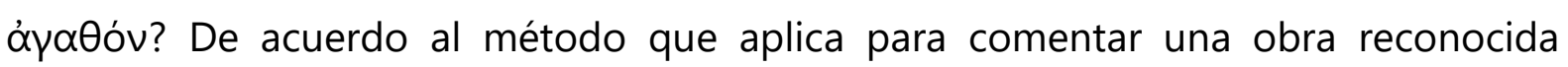
como una auctoritas, Tomás se apega a descubrir el hilo conductor que manifestará la unidad del De divinis nominibus. Se trata de un principio de orden que debe estructurar todas las partes del texto, de tal suerte que cada proposición aparezca como un elemento que se inscribe orgánicamente en el todo, del cual es un momento casi necesario. Este principio unificador es de tipo doctrinal, y en absoluto contextual -como lo ve Balthasar-o estrictamente textual -como lo busca Y. de Andia, con razón en la perspectiva que le es propia-. Sin desconocer el peso de la historia, el Aquinate trabaja sobre otro plano, que podríamos calificar como conceptual. Esto lo lleva a distribuir los nombres divinos en tres procesiones que corresponden a las tres series de implicaciones, de las cuales la Bondad creadora es la causa en el universo que ella crea:

Vemos que, desde la divina bondad, tres [efectos] son atribuidos a las cosas: en primer lugar, que en sí sean y se perfeccionen; en segundo lugar, que se relacionen entre ellas; en tercer lugar, que se ordenen a un $\mathrm{fin}^{25}$.

\footnotetext{
${ }^{23}$ Cf. In De div. nom., cap. XIII, lect. 1 (éd. Marietti, n 967): «Deus autem dicitur simpliciter perfectus, quia simpliciter omnia in seipso praehabet, sicut effectus praeexistunt in causa».

${ }^{24}$ Cf. Sum. theol., I ${ }^{a}$, q. 44, a. 1, 3, y 4.

${ }^{25}$ In De div. nom., cap. IV, lect. 1 (éd. Marietti, $\mathrm{n}^{\circ}$ 262): «tria videmus ex divina bonitate esse rebus attributa: primo quidem, ut in se sint et perficiantur; secundo, ut ad invicem comparentur; tertio, ut ordinentur in finem».
} 
El ser y la perfección de las cosas en sí mismas serían, en términos más sistemáticos, su actualidad primera y segunda, luego, su orden mutuo dentro de la creación, y, por último, su orden al fin, es decir, a Dios mismo. El Aquinate esboza aquí una parábola que, iniciando en la bondad divina, instituye el ser en acto de las cosas, explica sus relaciones mutuas y vuelve a su fuente, que será la unidad divina, una en sí y unificante para los demás. Aplicados a Dios, los nombres así obtenidos forman un círculo sobre el cual, por así decir, vienen a desfilar los tres cortejos, al principio de los cuales se hallan sucesivamente lo existente o «Lo que es» (ó

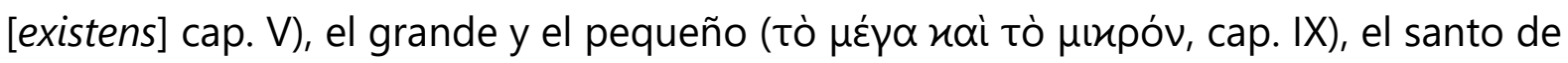

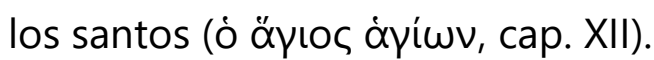

Veamos cómo santo Tomás reconstituye la primera de las tres series, aquella que concierne a los predicados que consideramos primero en el ser y en la perfección de las cosas en sí mismas:

Si se consideran, en cambio, las mismas cosas en sí, lo primero y común que en ellas encontramos es el ser; lo segundo, el vivir; lo tercero, el conocer; lo cuarto, lo que es justo o virtuoso. $Y$ según este orden, se prosigue acerca de los nombres divinos: en primer lugar, ciertamente después de lo bueno, acerca del ente (en el quinto capítulo); en segundo lugar, acerca de la vida (en el sexto); en tercer lugar, acerca de la sabiduría (en el séptimo); en cuarto lugar, acerca de la virtud y de la justicia (en el octavo $)^{26}$.

Esse, vivere, cognoscere: se reconoce inmediatamente la tríada dionisiana y neoplatónica de las perfecciones puras, a las cuales se agrega aquí la virtus, con su doble sentido de capacidad de obrar y de rectitud en la acción. La secuencia se comprende evidentemente según la universalidad lógica, con respecto a la cual el ente es primero; pero lo que -antes que al mismo Aquinate- importaba ya al Pseudo Dionisio es la intensidad ontológica. Es por esto que puede escribir, en el capítulo V:

Más principalmente que todo el resto, parece, Dios es celebrado con justa razón como El que es $[E x 3,14]$ de acuerdo al más anciano de sus otros dones ${ }^{\mathrm{VII}} 27$.

\footnotetext{
${ }^{26}$ In. De div. nom., cap. IV, lect. 1 (éd. Marietti, $n^{\circ} 263$ ): «Si autem ipsae res in se considerentur: primum et communius, quod in eis invenitur, est esse; secundo, vivere; tertio, cognoscere; quarto iustum esse vel virtuosum. Et secundum hunc ordinem, de divinis nominibus prosequitur: primo quidem post bonum, de ente in 5 capitulo; secundo, de vita in 6; tertio, de sapientia in 7; quarto, de virtute et iustitia in 8».

VII «Plus principiellement que tout le reste, semble-t-il, Dieu est célébré à bon droit comme Celui qui est $[E x 3,14]$ d'après le plus ancien de ses autres dons».
} 
Para el autor del tratado Sobre los nombres divinos, el ser «existente» O «ente» $(\omega ̋ v)$ es así el atributo más "anciano» que es preciso atribuir a Dios, pero solamente desde el punto de vista -que para él resulta secundario- de los dones que Dios hace a las creaturas. Volveremos -en nuestra segunda parte- al largo comentario de santo Tomás sobre esta tesis y su justificación. Relevemos simplemente ahora que él discierne de inmediato en la fórmula «es celebrado [...] como El que es» (sicut existens [...] laudatur, según la traducción de la que disponía) una citación del famoso «Qui est misit me ad vos» del libro del Éxodo:

De esto concluye, pues, su propósito principal, esto es, que Dios conveniente y principalmente -antes de todos los otros nombres- es alabado como existente, como desde el más digno de sus dones. Y que así sea alabado principalmente es evidente en Ex 3, donde se dice "El que es me envió a ustedes"28.

«El más digno de sus dones»: santo Tomás subraya la primacía de «el existente» entre las perfecciones que atribuimos a la causa primera a partir de sus efectos. Bajo este registro, el ser precede a todos los otros nombres divinos.

Pero, ¿cómo debemos comprender esta primacía? Según la reconstrucción

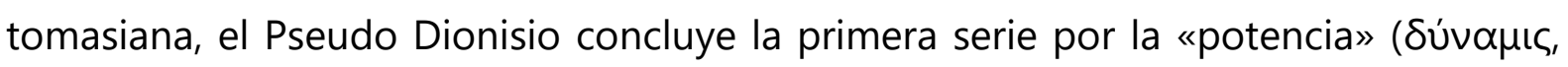
virtus), cuya eficacia y universalidad describe así:

También esta distribución ( $\left.\delta \iota^{\prime} \delta o \sigma \iota \varsigma\right)$ infinitamente potente de Dios penetra todos los entes y ninguno está totalmente privado de alguna potencia, pero cada uno posee una potencia o intelectual o racional o sensible o vital o esencial. $Y$ el hecho mismo de ser una potencia, si se permite decirlo, lo tiene, para ser, de la Potencia superesencial $^{\text {VIII } 29}$.

\footnotetext{
${ }^{27}$ Pseudo-Denys l'Aréopagite, Les Noms divins, V, § 5, I. 16-18, 820 B (SC 579, p. 18-19): «ПóvtwV oûv

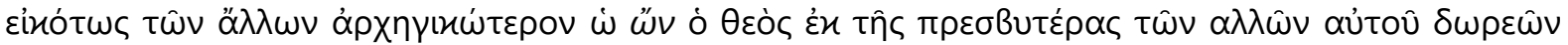

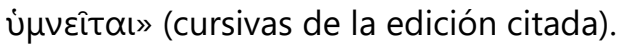

${ }^{28}$ In De div. nom., cap. V, lect. 1 (éd. Marietti, $n^{\circ} 635$ ): «Ex hoc ergo concludit principale propositum, scilicet quod Deus convenienter, principalius prae omnibus aliis nominibus, laudatur sicut existens, quasi ex digniore donorum suorum. Et quod principalius sic laudetur, patet Exod. 3, ubi dicitur: "Qui est misit me ad vos".»

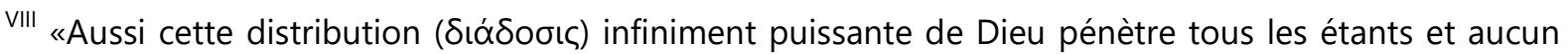
étant n'est totalement privé de quelque puissance, mais chacun possède une puissance ou intellectuelle ou raisonnable ou sensible ou vitale ou essentielle. Et le fait même d'être une puissance, $s^{\prime}$ il est permis de le dire, il le tient, pour être, de la Puissance suressentielle».

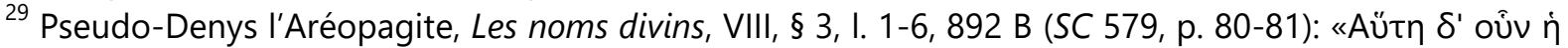

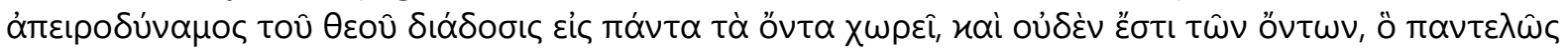


Todo ente creado goza, entonces, «de cierta potencia», proporcionada a su naturaleza, que recibe de la «Potencia superesencial» de Dios. Ahora bien, la potencia de un ente, se trate de la creatura o a fortiori del creado, no se podría agregar a él desde el exterior, sino que debe resultar de su ser. Por esto, el lector puede legítimamente inferir que el ser del ente creado, lejos de limitarse a hacerlo existir, está dotado de una potencia activa virtual recibida de la potencia creadora, la cual coincide con el Ser del creador. El comentario tomasiano va en esta dirección:

Así pues, concluye que la distribución de la virtud divina, a causa de su infinidad, procede hacia todas las cosas existentes y no hay ningún existente que no tenga alguna virtud; pero es preciso que tenga o una virtud intelectual, como los ángeles, o racional, como los hombres, o sensible, como los animales, o vivificante, como las plantas, o substancial, como las otras cosas; y no sólo los existentes, sino también el mismo ser tiene la virtud para que esto sea, por la virtud supersubstancial de Dios. $Y$ dice, si se permite decir, que no así propiamente se dice que el ser [esse] sea, sino que, por el ser [esse], algo sea ${ }^{30}$.

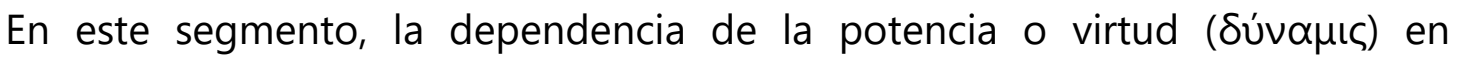
relación al ser (દîval) es más sugerida que afirmada. Pero el Doctor angélico, en el capítulo $\mathrm{V}$, había construido en la misma óptica el sintagma virtus essendi, para precisamente poner en principio que el dinamismo del ens reposa sobre su esse, de una manera proporcional a la intensidad de éste:

Todas las otras cosas, como se dijo antes, tienen un ser recibido y participado, y por esto no tienen el ser según toda la virtud de ser, sino que sólo Dios -que es mismo Ser subsistente- tiene el ser según toda la virtud de ser; y esto es lo que [Dionisio] dice, que por eso Dios puede ser causa del ser de todas las cosas ${ }^{31}$.

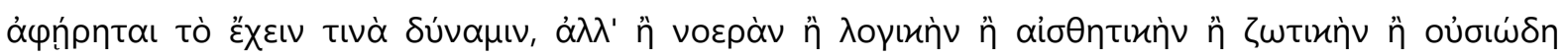

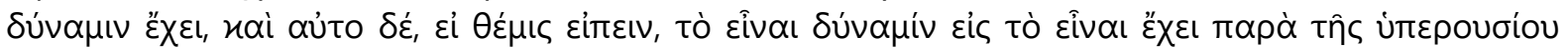

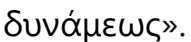

${ }^{30}$ In De div. nom., cap. VIII, lect. 1 (éd. Marietti, $\mathrm{n}^{\circ}$ 751): «Sic igitur concludit quod distributio divinae virtutis, propter sui infinitatem, procedit ad omnia existentia et nullum est existens quod non habeat aliquam virtutem; sed oportet quod habeat aut virtutem intellectualem, sicut Angeli aut rationalem, sicut Homines aut sensibilem, sicut Animalia, aut vivificam, sicut Plantae aut substantialem, sicut Alia; et non solum existentia, sed etiam ipsum esse habet virtutem ad hoc quod sit, a supersubstantiali Dei virtute. Et dicit, si fas est dicere, quia non sic proprie dicitur quod esse sit, sed quod per esse, aliquid sit».

${ }^{31}$ In De div. nom., cap. V, lect. 1 (éd. Marietti, n 629): «Omnia autem alia, sicut superius dictum est, habent esse receptum et participatum et ideo non habent esse secundum totam virtutem essendi, sed 
Si, pues, Dios es «causa de ser» (causa essendi), lo es en virtud de su «potencia de ser» (virtus essendi); pero ésta sólo justifica la causalidad creadora porque resulta del «mismo Ser subsistente» (ipsum esse subsistens), en quien el esse es al máximo, porque está totalmente indeterminado ${ }^{32}$, es decir, exento de toda limitación. Al contrario, la creatura, habiendo un esse «recibido y participado», su «potencia de ser» será limitada a la determinación de la forma substancial o accidental de otro ente, por medio de la generación o de la alteración. Es por esto que la creación propiamente dicha resta un privilegio divino incomunicable ${ }^{33}$.

La potencia creadora arraiga así en la infinidad del Ser divino: hasta aquí, los dos maestros están de acuerdo. Se oponen, en cambio, en la relación del esse a la bondad que gobierna el ejercicio de la «potencia de ser». Para el Areopagita, el ser se atribuye a Dios porque funda el primero de sus dones; pero es dominado por la bondad porque ésta explica la donación. En cuanto a la realidad de Dios en sí mismo, más allá de su capacidad creadora, ésta está por encima de todo conocimiento inteligible:

Porque, si todos los conocimientos son conocimientos de los entes y se terminan en los entes, el que es más allá de toda esencia trasciende asimismo todo conocimiento ${ }^{\mathrm{IX}} 34$.

solus Deus, qui est ipsum esse subsistens, secundum totam virtutem essendi, esse habet; et hoc est quod dicit, quod ideo Deus potest esse causa essendi omnibus».

${ }^{32}$ Cf. Sum. theol., $l^{a}$, q. 11 , a. 4 c.: «Est enim maxime ens, inquantum est non habens aliquod esse determinatum per aliquam naturam cui adveniat, sed est ipsum esse subsistens, omnibus modis indeterminatum».

${ }^{33}$ Respecto de esto, cf. I. E. M. Andereggen, La metafísica de santo Tomás en la Exposición sobre el De divinis nominibus de Dionisio Areopagita..., p. 21-22: «Dios no es ser participado, limitado, su "virtus essendi" es total. El ser en la creatura será participado, finito, limitado; su poder de ser sí mismo llega hasta un cierto punto. Los entes son seres de un modo. Por eso todo ser de cualquier creatura es menos que el Ser, y estaba y está ya en el Ser como en la plenitud de sí mismo, sin la limitación de modo y poder».

IX «Car si toutes les connaissances sont connaissances des étants et se terminent aux étants, celle qui est au-delà de toute essence, transcende aussi toute connaissance».

${ }^{34}$ Pseudo-Denys l'Aréopagite, Les noms divins, I, § 4, I. 59-62, 593 A (SC 578, p. 340-341): «Eỉ үà $\rho$ ai

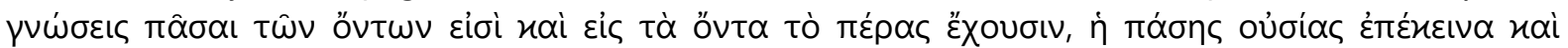

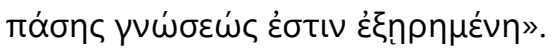


Al contrario, para el Aquinate, cuando escribe como autor y no como comentador, «Aquel que es» (Qui est) es el más propio de los nombres divinos, por dos razones que conciernen directamente nuestra problemática. Ante todo, porque la bondad presupone el ser, es decir, no podría ser primera:

El nombre bien es el principal nombre de Dios en cuanto es causa, sin embargo, no simplemente, pues absolutamente la intelección de la causa supone la del $\operatorname{ser}^{35}$.

Luego, «Aquel que es» conviene a Dios máximamente, porque expresa de la mejor manera que nos es posible la identidad del esse y de la esencia que caracteriza su estatuto ontológico propio:

\begin{abstract}
Este nombre Aquel que es máximamente es el nombre propio de Dios por tres razones. En primer lugar, a causa de su significación: en efecto, no significa ninguna forma, sino el mismo ser, de donde que, dado que el ser de Dios es su esencia, y esto no conviene a ningún otro [ente], como ya se ha dicho, es claro que, entre todos los otros nombres, éste máxima y propiamente nombra a Dios: cada cosa, en efecto, es denominada por su forma ${ }^{36}$.
\end{abstract}

La «forma» de Dios es su esse, libre de toda delimitación formal, y es por esto que el tetragrama YHWH es su nombre más apropiado, absolutamente hablando, y no en relación a su causalidad creadora. Étienne Gilson ha marcado bien la distancia que separa a Tomás del Pseudo Dionisio a este respecto:

\footnotetext{
${ }^{35}$ Sum. theol., ${ }^{a}$, q. 13, a. 11 ad 2: «Hoc nomen bonum est principale nomen Dei inquantum est causa, non tamen simpliciter: nam esse absolute praeintelligitur causae». Fran O'Rourke ha comentado muy bien el alcance de esta observación en Pseudo-Dionysius and the Metaphysics of Aquinas..., p. 109-110: «lt is because Being is a pre-condition for the efficacity of any cause whatsoever that it is in itself absolutely primary. It is universally the most fundamental of all notions and, more radically, is primary among perfections. To be understood as cause, something must first be conceived as in some manner existing. To exert the power of causality a cause must already be, even in the case of a final cause only by an intentional existence». T.-D. Humbrecht comenta sobre esto en Théologie négative et noms divins chez saint Thomas d'Aquin, p. 439: «La bonté est de l'être, et c'est pourquoi l'être ne saurait être placé loin de la bonté, ni l'un et l'autre de Dieu».

${ }^{36}$ Sum. theol., $l^{a}$, q. 13, a. 11 c.: «hoc nomen Qui est triplici ratione est maxime proprium nomen Dei. Primo quidem, propter sui significationem. Non enim significat formam aliquam, sed ipsum esse. Unde, cum esse Dei sit sua essentia, et hoc nulli alii conveniat, ut supra ostensum est, manifestum est quod inter alia nomina hoc maxime proprie nominat Deum: unumquodque enim denominatur a sua forma».
} 
...en Dionisio mismo (en la medida que se osa precisar un pensamiento difícil de captar) el ser, el esse, no es todavía la perfección formal suprema. Antes de él se encuentra el bien, que se deriva hacia los entes bajo la forma del esse. El ens es el ser (esse) comprometido en sus participaciones. Para santo Tomás, no hay nada por encima del esse. El acto propio en virtud del cual el ente es, nos es dado como una culminación y perfección de la esencia de este ente. Presencia íntima en el ente del Ipsum purum esse -que lo habita como la causa penetra su efecto- este esse es una virtud puesto que es supremamente acto $^{37}$.

Nos queda determinar si y cómo el Aquinate prepara, o incluso anticipa, esta superación del Areopagita en el comentario que nos ha dejado.

\section{El bien y el ser en el cuerpo del comentario de Los nombres divinos}

a) El bien en relación al esse

Tomás está dispuesto a conceder a Dionisio, como hemos visto, que el motivo próximo de la creación se encuentre en la bondad divina ${ }^{38}$; pero esta anterioridad relativa del bien en el orden de la causalidad creadora no nos autoriza a postular una anterioridad absoluta del bien entre los nombres divinos. Si el Pseudo Dionisio da ese paso, es, en realidad, a causa de un error filosófico que proviene de su platonismo:

...hay que considerar que los platónicos, que no distinguían la materia de la privación, la ponían en el orden de los no-entes, como dice Aristóteles en el primer libro de la Física. En efecto, la causalidad del ente sólo se extiende a los entes. Así pues, según ellos, la causalidad del ente no se extendía a la materia prima, hacia la cual, sin embargo, se extiende la causalidad del bien. Signo de esto es que la misma

\footnotetext{
${ }^{37}$ Étienne Gilson, «Virtus Essendi», in Mediaeval Studies 26 (1964), p. 1-11 [p. 11]. Cf. aussi Ghislain Lafont, Structures et méthodes dans la "Somme théologique» de saint Thomas d'Aquin, "Textes et études théologiques», Paris, Éditions du Cerf, ${ }^{2} 1996$, p. 59: «En posant, contre Denys et au nom de la Révélation de l'Exode, la primauté de l'être sur le bien en Dieu, saint Thomas s'orientait dans une perspective en somme éloignée de l'apophatisme».

${ }^{38} \mathrm{Cf}$. Sum. theol., I ${ }^{a}$, q. 44, a. 4 c.: "Sed primo agenti, qui est agens tantum, non convenit agree propter acquisitionem alicuius finis; sed intendit solum communicare suam perfectionem, quae est eius bonitas. Et unaquaeque creatura intendit consequi suam perfectionem, quae est similitudo perfectionis et bonitatis divinae. Sic ergo divina bonitas est finis rerum omnium».
} 
máximamente apetece el bien. Ahora bien, es propio del efecto que se vuelva por el deseo hacia su causa. Así pues, el bien es más universal y alto en cuanto causa que el ente, porque [su causalidad] se extiende a más [objetos] $]^{39}$.

La materia «desea» el bien, y, entonces, se refiere a él; pero la materia es un no-ente, $y$, entonces, no se relaciona en ningún caso con el ente; luego, algún noente desea el bien. Si esta conclusión fuera verdadera, comportaría dos implicaciones. La primera sería la mencionada por santo Tomás, a saber, que la causalidad del bien sería más universal que la del ente y que la del esse, que es su principio. La otra consecuencia sería que el deseo del bien, en la materia, tendría por sujeto un no-ente, y por término, una instancia superior al ente, que nuestra inteligencia sólo podría captar -sit venia verbo- como un súper-ente, que sería, para nosotros, un no-ente. Pero la ligazón que uniría un no-ente (inferior al ente) con un súper-ente (superior al ente) sólo podría ser una relación de razón entre dos externos negativos. Más ampliamente, si el bien estuviera más allá del ente y del esse, su causalidad final sería aquella de un objeto que sólo podríamos pensar como no-ente o no-esse, incluso si la negación constitutiva del bien debiera supuestamente incluir una sobreabundancia o una super-realidad: esta trascendencia, significada por el prefijo úrép jamás sería la del ser. El enfoque del Pseudo Dionisio lo arrastra así, volens nolens, hacia un apofatismo que ignora la realidad, a la vez, del amor y del bien.

La superioridad pretendida del bien sobre el ente-esse termina, entonces, por destruir lo que afirma; por esto, la tesis dionisiana debe ser dada vuelta. Santo Tomás no duda en hacerlo, discreta pero eficazmente, en un rodeo de su comentario sobre el capítulo IV. El portavoz de los nombres divinos allí notaba esto:

${ }^{39}$ In De div. nom., cap. III, lect. un. (éd. Marietti, $\mathrm{n}^{\circ}$ 226): «...considerandum est quod Platonici, materiam a privatione non distinguentes, ponebant eam in ordine non-entis, ut dicit Aristoteles in I Physicorum. Causalitas autem entis non se extendit nisi ad entia. Sic igitur secundum eos causalitas entis non se extendebat ad materiam primam, ad quam tamen se extendit causalitas boni. Cuius signum est quod ipsa maxime appetit bonum. Proprium autem est effectus ut convertatur per desiderium in suam causam. Sic igitur bonum est universalior et altior causa quam ens, quia ad plura se extendit». 
...la denominación de Bien que los teólogos reservan, de una manera trascendente, a excepción de todo el resto, a la Deidad supradivina, llamando Bondad, según me parece, a la Existencia teárquica misma, y en razón que, por el hecho de ser, el Bien en tanto que Bien esencial, extiende su bondad a todos los entes ${ }^{\times 40}$.

La traducción utilizada por el Aquinate vuelca «la Existencia teárquica» (Tìv

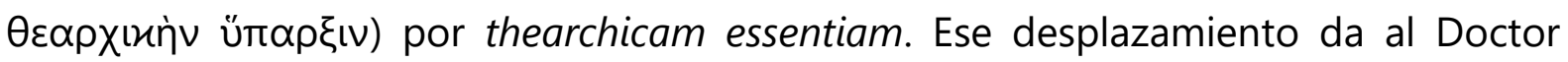
angélico la ocasión de situar el bien delante del esse. En el caso de Dios, la bondad se identifica desde el principio con la esencia, como lo afirma la versión defectuosa:

«Sólo Dios es bueno» ${ }^{41}$. Y esto, a causa de dos cosas: la primera, ciertamente, porque la divina Esencia misma es la misma bondad, lo cual no acaece en las otras cosas. En efecto, Dios es bueno por su esencia, todas las otras cosas, en cambio, [son buenas] por participación; cada uno es bueno, en efecto, de acuerdo a que es una cosa en acto; sin embargo, a Dios le es propio ser su esse, de donde sólo él mismo es su bondad ${ }^{42}$.

Siendo Dios bueno por esencia, no es solamente bueno, sino que es idénticamente su propia bondad como y porque es su esse. Esta tesis tan típicamente tomasiana nos muestra que el comentario recurre sin vacilación a la metafísica del comentador para esclarecer el texto comentado. Este es el signo de una Expositio: sin dejar de ceñirse a la letra de la obra explicada, apunta en último término a descubrir la verdad, incluso solamente virtual, que ella contiene, y en absoluto únicamente a explorar el pensamiento del autor en causa. Aquí, la interpretación se apoya sobre el análisis metafísico del bien, el cual puede desarrollarse en dos etapas. En la primera,

$x$ «...la dénomination de Bien que les théologiens réservent, d'une manière transcendante, à l'exception de tout le reste, à la Déité supra-divine, en appelant Bonté, à ce qu'il me semble, I'Existence théarchique elle-même, et parce que, par le fait d'être, le Bien en tant que Bien essentiel, étend sa bonté à tous les étants».

40 Pseudo-Denys I'Aréopagite, Les noms divins, IV, § 1, I. 1-6, 693 B (SC 578, p. 428-429): «tr̀v

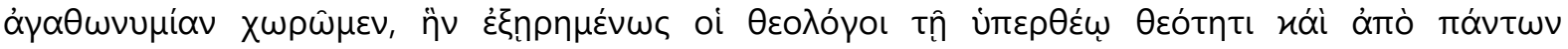

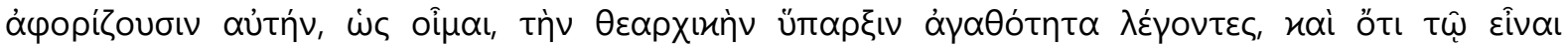

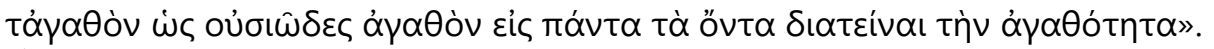

${ }^{41}$ Lc 18, 19.

${ }^{42}$ In De div. nom., cap. IV, lect. 1 (éd. Marietti, n² 269): «"Nemo bonus nisi solus Deus". Et hoc, propter duo: primo, quidem, quia ipsa divina Essentia est ipsa bonitas, quod in aliis rebus non contingit: Deus enim est bonus per suam essentiam, omnia vero alia per participationem; unumquodque enim bonum est, secundum quod est res actu; Deo autem proprium est quod sit suum esse, unde ipse solus est sua bonitas». 
es preciso resolver el bien en el esse, lo que santo Tomás hace, en la Summa theologiae, de la siguiente manera: lo bueno es lo apetecible; ahora bien, la apetibilidad depende de la perfección; pero la perfección se funda sobre la actualidad; y la actualidad de la cosa proviene de su acto de ser; ergo, la bondad de una realidad deriva de su esse ${ }^{43}$. A partir de allí, es fácil mostrar, en la segunda etapa, que lo que, por esencia, es el Ipsum esse subsistens, es aún, por esencia, su propia bondad.

Esta resolutio del bien en el esse, diferenciada según que se trate del creador o de la creatura, parece tan importante para el Aquinate que ofrece una segunda presentación a su lector. La lección continúa, pues, así:

Igualmente, las otras cosas -aunque en cuanto son, son buenas-, sin embargo, alcanzan la perfecta bondad por algo añadido sobre su ser; pero Dios tiene el complemento de su bondad en su mismo $\operatorname{ser}^{44}$.

De manera un poco abreviada -quizás porque el comentario estaba destinado a especialistas, bachilleres sentenciarios o maestros- el Doctor angélico recuerda, en la primera mitad de la frase, que la bondad se articula, en las creaturas, en dos planos: el de la bondad substancial, que resulta inmediatamente de la actuación de la esencia por el esse, pero que es imperfecta; y el de la bondad accidental, que «se agrega» al esse de las substancias y que, llevando al suppositum a su acabamiento, es su bondad perfectiva, sobre todo si, siendo un viviente, este agregado es la más alta de sus operaciones vitales. Por esto, el ente substancial, teniendo el esse en sí, es un ens simpliciter, mientras que el ente accidental, no teniendo el esse en sí, sino en otro, es un ens secundum quid. Inversamente, en cambio, la substancia en tanto que tal, que sólo tiene por su ser una bondad relativa, es un bonum secundum quid, mientras que la substancia perfeccionada por sus accidentes propios últimos,

\footnotetext{
${ }^{43}$ Cf. Sum. theol., I ${ }^{a}$, q. 5, a. 1 c.: «Ratio enim boni in hoc consistit, quod aliquid sit appetibile: unde Philosophus, in I Ethic., dicit quod bonum et quod omnia appetunt. Manifestum est autem quod unumquodque est appetibile secundum quod est perfectum: nam omnia appetunt suam perfectionem. Intantum est autem perfectum unumquodque, inquantum est actu: unde manifestum est quod intantum est aliquid bonum, inquantum est ens: esse enim est actualitas omnis rei, ut ex superioribus patet».

${ }^{44}$ In De div. nom., cap. IV, lect. 1 (éd. Marietti, $n^{\circ} 269$ ): «Item, res aliae, etsi inquantum sunt, bonae sint, tamen perfectam bonitatem consequuntur per aliquod superadditum supra eorum esse; sed Deus in ipso suo esse, habet complementum suae bonitatis».
} 
accediendo así a su bondad integral, es un bonum simpliciter ${ }^{45}$. En Dios, esta composición entre un esse constitutivo y un ser en acto sobreañadido no puede tener lugar, porque su Ser simple y subsistente no sufre alguna «adición», siendo infinitamente simple y perfecto por sí mismo.

Un tercer argumento opone la necesidad, en la creatura, de una finalidad extrínseca a la imposibilidad de este tipo de finalidad en Dios:

Igualmente, las otras cosas son buenas en orden a alguna otra cosa, que es el fin último; Dios, en cambio, no se ordena a algún fin fuera de sí. Así pues, lo primero que es propio de la divina bondad es que la misma bondad es la esencia divina; lo segundo propio suyo es que extiende la bondad a todas las cosas, que se dicen por participación ser derivadas de Aquel que se dice por esencia ${ }^{46}$.

Este razonamiento procede de manera menos directamente ligada al esse que los dos precedentes. Siendo Dios el primero en el orden de la causalidad final, es imposible que sea ordenado a un fin que le fuera superior; al contrario, es él que debe ser el fin de todos los entes creados. Pero, siendo la posesión del fin la razón por la que un ente es bueno, resulta que, primero, Dios es bueno en virtud de su esencia y, luego, que las creaturas son buenas en tanto que ellas participan de la bondad divina. La actualidad de ser no juega aquí ningún rol directo en la inferencia misma. No obstante, es preciso notar que la conclusión relativa a la «segunda propiedad» toca a la relación de derivación que une las cosas a «Aquel que se dice por esencia». En la edición citada (no es la más reciente), el pasaje adolece de algo de claridad: la atribución por esencia ¿concierne a la bondad, como lo sugiere el contexto inmediato, o bien mira a la esencia, como lo indica la sintaxis de la

\footnotetext{
${ }^{45}$ Este quiasmo es desarrollado con gran claridad en Sum. theol., $l^{a}$, q. 5, a. 1, ad 1 : «... per suum esse substantiale dicitur unumquod ens simpliciter. Per actus autem superadditos, dicitur aliquid esse secundum quid, sicut esse album significat esse secundum quid [...]. Sed bonum dicit rationem perfecti, quod est appetibile : et per consequens dicit rationem ultimi. Unde id quod est ultimo perfectum, dicitur bonum simpliciter. Quod autem non habet ultimam perfectionem quam debet habere, quamvis habeat aliquam perfectionem, inquantum est actu, non tamen dicitur perfectum simpliciter, nec bonum simpliciter, sed secundum quid».

${ }^{46}$ In De div. nom., cap. IV, lect. 1 (éd. Marietti, $\mathrm{n}^{\circ}$ 269): «Item, res aliae sunt bonae per ordinem ad aliquid aliud, quod est ultimus finis; Deus autem non ordinatur ad aliquem finem extra se. Sic igitur, primum quod est proprium divinae bonitatis est quod ipsa bonitas est essentia divina; secundum proprium eius est quod extendit bonitatem ad omnia, quae per participationem dicuntur derivari ab Eo quod per essentiam dicitur».
} 
proposición relativa? Independientemente de esta pequeña dificultad exegética, la «primera propiedad» arraiga la bondad divina en la esencia divina, que el primer argumento identificaba con el esse divino.

La inversión del orden de prioridad dionisiano entre el bien y el ser vuelve a aparecer más adelante en el comentario del capítulo IV. El Pseudo Dionisio escribe esto en la sección 20:

O mejor, todos los entes serán más o menos, en la medida de su participación del Bien; en efecto, teniendo en vista el hecho de ser (bueno), lo que no lo es en absoluto y de ningún modo, no será tampoco ${ }^{\mathrm{Xl}} 47$.

No sabríamos decir más claramente que la participación del Bien es, para los entes, la medida de su ser. Pero santo Tomás relaciona sutilmente la dependencia de la bondad frente a la densidad del ente:

Dice, entonces, que todos los existentes tanto más o menos participan del ser, cuanto más o menos participan del bien, porque el ente en cuanto ente es bueno. Lo mismo es acerca del bien como también acerca del ente, ya que, si algo existe que no participara en modo alguno del mismo ser, se seguiría que de ningún modo sería ${ }^{48}$.

La primera proposición subordinada retoma el texto dionisiano, que funda el grado de ser de cada existente en la intensidad de su participación del bien. ¡Nada de más platónico hasta este preciso momento! Pero la justificación introducida por un quia -que hemos traducido por la conjunción «porque»- da un giro, sin casi decirlo, a la relación de dependencia. En efecto, afirmar, utilizando un léxico netamente aristotélico, que «el ente en cuanto ente es bueno», es vincular la bondad del ente a aquello por lo que el ente es tal; ahora bien, el principio constitutivo del ente, según la doctrina constante del Aquinate, es su esse. En la segunda frase del

$\mathrm{Xl}$ «Ou mieux, tous les étants seront plus ou moins, dans la mesure de leur participation au Bien; en effet, eu égard au fait de l'être (bon), ce qui ne l'est nullement ni en aucune façon ne sera pas non plus».

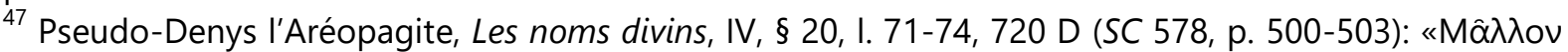

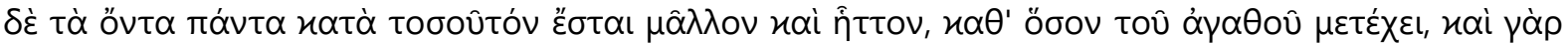

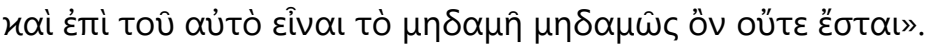

${ }^{48}$ In De div. nom., cap. IV, lect. 16 (éd. Marietti, n 509): «Dicit, ergo, quod omnia existentia intantum magis et minus de esse participant, inquantum magis et minus participant bono; quia ens inquantum ens est bonum. Item est de bono sicut et de ente; quia in ipso esse si aliquid nullo modo existit participans, sequitur quod nullo modo erit». 
fragmento que hemos citado, la explicación introducida de nuevo por un quia -que hemos volcado esta vez por la locución conjuntiva «ya que»- completa la inversión: la cosa existe por participación del ser mismo (in ipso esse); y «lo mismo es acerca del bien como también acerca del ente», la bondad de esta cosa dependerá de la difusión, en ella, se su esse. Sin herir de frente a la auctoritas de aquel que era considerado comúnmente, en el siglo XIII, como el discípulo de san Pablo, el Maestro Tomás no teme, sin embargo, releerlo dentro de su metafísica, en absoluto porque ésta le sea propia, sino porque -con justicia- le parece verdadera.

\section{b) El esse, perfección intensiva primera}

La primacía del esse sobre toda otra perfección está fuertemente acentuada en la primera de las tres lecciones sobre el capítulo $V$, que va a inscribirlo en una ontología -y no más en una agathología- de la participación. La ocasión de esta transcripción se ofrece por la tesis dionisiana según la cual el ser es «el más anciano» de los dones divinos:

...y el ser ha sido emitido antes que las otras participaciones suyas. Y, en sí mismo y por sí mismo, el ser es más anciano que la vida en sí, la sabiduría en sí, la semejanza divina en sí; y todos los otros (atributos) de los cuales los entes participan, todo participando del ser antes que de todos (estos atributos), o, mejor, las cosas mismas y por sí mismas, de las cuales los entes participan, participan del ser en sí y por sílll 49.

La anterioridad del ser sobre las otras perfecciones puras, en los entes, reenvía así a la primacía de la participación del ser sobre toda otra participación: antes de participar de la vida o de la sabiduría, la creatura debe primero participar del esse. Para santo Tomás, estas diferentes participaciones no se agregan las unas a las otras

\footnotetext{
XII «...et l'être a été émis avant les autres participations de lui. En soi-même et par soi-même, l'être est plus ancien que la vie en soi, la sagesse en soi, la ressemblance divine en soi; et tous les autres (attributs) dont les étants participent, tout en participant avant tous (ces attributs) à l'être, ou plutôt les choses elles-mêmes et par elles-mêmes, dont les étants participent, participent à l'être en soi et par soi».

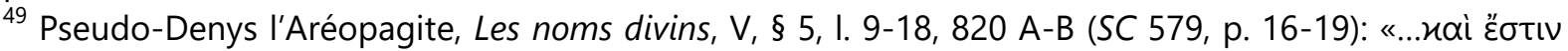

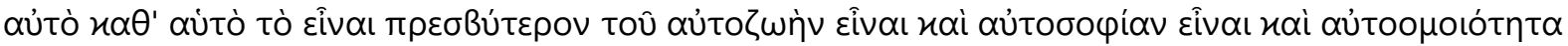

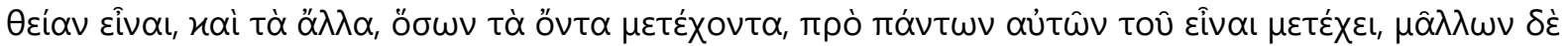

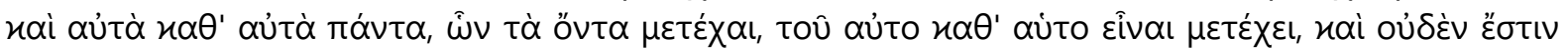

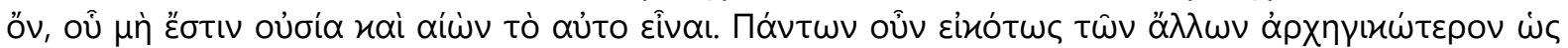

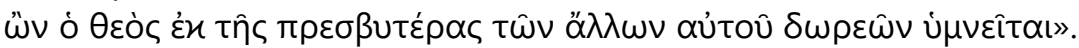


como formalidades distintas en la cosa, como si, por ejemplo, la substancia espiritual fuera primero constituida en ente por el ser, luego en viviente por la vida y, por último, en inteligente por la sabiduría. Al contrario, las perfecciones posteriores al esse son también mediadas por el esse:

Si alguna causa es nombrada por su efecto, muy convenientemente es nombrada por el principal y más digno de sus efectos. Ahora bien, el ser mismo es, entre los otros efectos de Dios, el más digno y principal. Ergo, Dios, que sólo puede ser nombrado por nosotros a través de sus efectos, muy convenientemente es nombrado con el nombre de ente. Es esto, pues, lo que dice, que el mismo ser es propuesto a las creaturas para participar de él antes que de las otras participaciones de Dios. Cualquier perfección tenga la creatura, se vuelve por esto en participación de Dios, que como si se propusiera y ofreciera a todos a participar; pero, en primer lugar, se participa en cuanto al mismo ser que de cualquier otra perfección, y el mismo ser es por sí anciano, esto es, primero y más digno que lo que es ser la vida por sí, y que lo que es ser la sabiduría por sí y, que lo que es ser semejanza divina por sín ${ }^{\prime 0}$.

La clave de este texto y, mucho más allá, de toda la metafísica tomasiana es la reducción al ser mismo (ipsum esse) de toda otra perfección (quamcumque aliam perfectionem). «La ancianidad» ( $\pi \rho \varepsilon \sigma B u ́ \tau \varepsilon \rho o v)$ califica aquí al esse de manera axiológica, y no puramente genética, ni incluso simplemente existencial. La substancia espiritual es, pues, viviente e inteligente porque su esse se expande en ella en vida y en inteligencia, en la proporción fijada por la esencia de Miguel o de Gabriel. Probablemente, tal o cual substancia compuesta -este herrerillo o esta rosatendrá tal o cual naturaleza y, con ella, tales o cuales propiedades típicas, porque su esse se despliega en ella de esta manera, según la medida que le asigna su esencia.

50 In de div. nom., cap. $\mathrm{V}$, lect. 1 (éd. Marietti, $\mathrm{n}^{\circ}$ 633): «Si qua causa nominetur a suo effectu, convenientissime nominetur a principali et dignissimo suorum effectuum. Ipsum autem esse inter alios Dei effectus est principalius et dignius. Ergo Deus, qui a nobis nominari non potest nisi per suos effectus, convenientissime nominatur nomine entis. Hoc est ergo quod dicit, quod ipsum esse propositum est creaturis ad participandum ante alias Dei participationes. Quamcumque enim perfectionem creatura habeat, fit per hoc in Dei participatione, qui quasi proponitur et offertur omnibus ad participandum; sed per prius participatur quantum ad ipsum esse, quam quamcumque aliam perfectionem : et ipsum per se esse est senius, idest primum et dignius eo quod est per se vitam esse et eo quod est per se sapientiam esse et eo quod est per se similitudinem divinam esse». 
Esta anterioridad o, para retomar la palabra del comentador, esta «dignidad» del ser, exigía que se detuviera allí, lo que nos vale uno de los lugares mayores del corpus thomisticum sobre este tema. En el pasaje del Pseudo Dionisio que hemos citado, el Aquinate discierne dos pruebas de la excelencia del esse $e^{51}$. Aquí su explicación de la primera:

En primer lugar, a través de esto: que cualquier cosa que participa de otras participaciones, primero lo hace del mismo ser; en efecto, ante todo se intelige algo como ente que como uno, viviente o sabio ${ }^{52}$.

La primera de las participaciones es la del ente en el ser mismo (ipsum esse), porque, sin ésta, aquéllas son ontológicamente imposibles -sólo serían nada- y noéticamente impensables -serían ininteligibles-. Importa para nuestro objetivo relevar que el Maestro Tomás menciona aquí «el uno» (unum) entre las participaciones posteriores al ser: así, éstas no son solamente las perfecciones puras (vida, sabiduría, también amor), sino también las perfecciones trascendentales $-\mathrm{y}$, entonces, el bien- que deben su realidad y su inteligibilidad al esse. En las huellas de Cornelio Fabro, Christian Ferraro ve en este argumento «la emergencia» real, es decir, la trascendencia del esse respecto de las otras perfecciones en cuanto a su actualidad en el universo:

Antes que nada, se ve cómo para participar cualquier tipo de formalidad o perfección hace falta ante todo ser, es decir, constituirse como ente, y esto acaece en virtud de la participación del esse (genitivo objetivo: el esse como término del participar, como lo participado). Hasta aquí, se trata del momento "real" de la emergencia del esse como acto fundante $e^{53}$.

${ }^{51}$ Cf. In De div. nom., cap. V, lect. 1 (éd. Marietti, $n^{\circ}$ 635): «Quod autem per se esse sit primum et dignius quam per se vita et per se sapientia, ostendit dupliciter».

52 Ibid.: «primo quidem, per hoc quod quaecumque participant aliis participationibus, primo participant ipso esse: prius enim intelligitur aliquod ens quam unum, vivens, vel sapiens».

${ }^{53}$ Christian Ferraro, «La interpretación del esse en el "tomismo intensivo" de Cornelio Fabro», Espiritu 66, no 153 (2017), p. 11-70 [p. 38]. El P. Ferraro explicita aquí muy claramente dos consideraciones de Cornelio Fabro, que se encuentran respectivamente en Participation et causalité selon S. Thomas d'Aquin, Paris, Parole et Silence, ${ }^{2} 2015$, p. 227-228, y en "L'emergenza dello esse tomistico sull'atto aristotelico: breve prologo. L'origine trascendentale del problema», en L'atto aristotelico e le sue ermeneutiche. Atti del colloquio internazionale (Laterano, 17-18-19 gennaio 1989), A cura di Marcelo Sánchez Sorondo, Roma, Herder - Pontificia Università Lateranense, 1990, p. 149-177 [p. 173-174]. 
La otra prueba de la superioridad del esse que el Doctor angélico descubre en el texto dionisiano conjuga el registro platónico de la participación y el registro aristotélico de la actuación:

En segundo lugar, que el mismo ser se compara a la vida (y a otras cosas de este tipo) como lo participado al participante, pues también la misma vida es cierto ente y así el ser es anterior y más simple que la vida (y las otras cosas de este tipo) y se compara a ellas como su acto. Por esto dice que no sólo las cosas que participan de otras participaciones primero participan del ser, sino que -lo que es más- todas las cosas que son nombradas por sí mismas, como la vida por sí, la sabiduría por sí y otras de este tipo (de las cuales los existentes participan) participan del mismo ser por sín

Como todos saben, el principio generador del platonismo quería que las perfecciones presentes en los existentes participaran de un paradigma separado, de tal suerte que los vivientes fuesen tales por participación de la Vida en sí. En el Pseudo Dionisio, la multiplicidad de hipóstasis que resultaba normalmente de este postulado es superada y asumida -Hegel habría escrito aufgehoben- en la unicidad del ser. En su comentario, santo Tomás subraya -quod magis est- que estas hipotéticas formas o contenidos ideales sólo tendrían algo de consistencia por la participación del ser, al cual ellas deberían su actualidad si fueran reales. En todo caso, las determinaciones del ser, tales como el ser viviente, el ser sabio, pero también el ser herrerillo o el ser rosa, sólo son participaciones formales del acto de ser. Es en este sentido que el P. Ferraro, prosiguiendo su análisis el del P. Fabro, refiere este segundo argumento a lo que uno y el otro llaman la emergencia formal del esse:

Pero se ve también que no sólo los que participan de las demás formalidades tienen que participar primero del esse como condición y requisito imprescindible para poder participar de ellas, sino que las demás formalidades son ellas mismas participaciones con respecto al esse, participan del esse y solamente así se constituyen como formalidades eventualmente perfectivas de algún sujeto: no ha de escapar al atento

${ }^{54}$ In De div. nom., cap. V, lect. 1 (éd. Marietti, $n^{\circ} 635$ ): «Secundo, quod ipsum esse comparatur ad vitam, et alia huiusmodi sicut participatum ad participans: nam etiam ipsa vita est ens quoddam et sic esse, prius et simplicius est quam vita et alia huiusmodi et comparatur ad ea ut actus eorum. Et ideo dicit quod non solum ea quae participant aliis participationibus, prius participant ipso esse, sed, quod magis est, omnia quae nominantur per se ipsa, ut per se vita, per se sapientia et alia huiusmodi quibus existentia participant, participant ipso per se esse». 
lector la enorme fuerza de ese "quod magis est", que no está en el Ps.-Dionisio y sí en santo Tomás. Pues bien, este segundo aspecto expresa el momento "formal" de la emergencia del esse $e^{55}$.

«Emergencia real», «emergencia formal»: esta terminología forjada por Fabro, ¿no proyecta sobre las dos rationes del comentario tomasiano una distinción que les es extraña, y que transforma su simple dualidad en oposición marcada? Sin ninguna duda, no nos hemos aquí con un puro análisis textual, sino con una interpretación. Ésta, sin embargo, está plenamente justificada. En efecto, santo Tomás muestra sucesivamente, en el lugar citado, que el viviente debe, ante todo, participar del esse antes que participar de la vida; luego, que esta participación de la vida es, en él, actuada por el esse. Bajo el primer respecto, el esse juega el rol de principio existencial: sin el ser, no hay viviente. En cambio, bajo el segundo respecto, el mismo esse ejerce la función de principio formal originario: por el ser, la perfección de la vida es participada por el viviente. El viviente recibe así de su acto de ser todo lo que tiene de actualidad ontológica, su existencia real por un lado y su perfección formal por otro lado. Leídas de esta manera, las dos instancias del comentario tomasiano esclarecen particularmente bien las célebres fórmulas del Doctor angélico sobre la primacía del esse, en especial aquella que es contemporánea de la Expositio sobre el De divinis nominibus ${ }^{56}$ : «el ser mismo es el acto último que es participable por todas las cosas, pero él mismo no participa de nada» ${ }^{57}$. Rigurosamente, esta declaración significa que todos los modos y todos los tipos de ser en acto presentes en las cosas participan del esse. La rosa del jardín existe porque tiene ser; ella es una rosa porque participa del ser según esta esencia y no absolutamente según la del lilium; ella es

\footnotetext{
${ }^{55}$ C. Ferraro, «La interpretación del esse en el "tomismo intensivo" de Cornelio Fabro»..., p. 38-39.

${ }^{56}$ Según Jean-Pierre Torrell, Initiation à saint Thomas d'Aquin. Sa personne et son œuvre, Paris, Cerf, ${ }^{3} 2015$, p. 460, el Super librum Dionysii De divinis nominibus (al cual, pues, atribuye un título distinto del de la edición Marietti) debe ser situado «durant le séjour à Rome après mars 1266». Según el mismo autor, las Quaestiones disputatae De anima fueron redactadas aproximadamente un año más tarde, es decir, en 1266-1267 (cf. p. 440). Sería interesante investigar si la redacción del comentario sobre Los nombres divinos marca, o no, un jalón en el modo en el que santo Tomás comprende y expresa la primacía del esse, pero esta empresa desborda el marco del presente trabajo.

${ }^{57}$ S. Thomas, Q. De anima, q. 6, ad 2: «ipsum esse est actus ultimus qui participabilis ab omnibus; ipsum autem nichil participat».
} 
amarilla, porque este color es el que actúa ulteriormente su naturaleza en acto, y no el rojo o el blanco. Por participaciones sucesivas, el esse es así: «la actualidad de todos los actos y, por esto, la perfección de todas las perfecciones» ${ }^{58}$.

Es, pues, por la mediación del acto de ser que el suppositum real-es decir, la substancia subsistente integralmente considerada, en tanto que ella incluye la totalidad de sus formas accidentales y de sus operaciones- despliega toda la riqueza ontológica que le es propia en un instante dado. El comentario del Aquinate insiste fuertemente sobre esta economía de participación:

Y si éstos que son principios de otras cosas no son sino por participación del ser (per participationem essendi), mucho más aquellas cosas que participan de los mismos no son sino por participación del mismo ser (ipsius esse). Y así es evidente que Dios a través de su mismo ser (per ipsum esse) causa todas las cosas ${ }^{59}$.

Una segunda dimensión del esse aparece aquí, indisolublemente ligada a la primera: no sólo el acto de ser es, en la inmanencia del ente, la fuente de sus perfecciones, sino que también es, en la trascendencia de la creación y de la conservación de lo creado, el mediador trascendental de la causalidad divina. Decimos mediador porque el esse es participado por las formas y las operaciones del suppositum, participando él mismo del Ipsum esse subsistens; y decimos trascendental porque su actualidad originaria precede y funda la de las diferentes categorías en

${ }^{58}$ S. Thomas, Q. De potentia, q. 7, a. 2, ad 9: «esse est actualitas omnium actuum, et propter hoc perfectio omnium perfectionum». De acuerdo con J.-P. Torrell, Initiation à saint Thomas d'Aquin..., p. 439, «les Questions disputées De potentia datent du séjour de Thomas à Rome, très probablement de la première année de cette période (1265-66)». Encontrándose la cuestión 7 al principio del tercer tercio de la obra, ¿es posible que el Aquinate haya tomado la inspiración de esta secuencia así perfectamente labrada mientras que trabajaba en Los nombres divinos? En todo caso, la conclusión de este ad 9 cita al Pseudo Dionisio: «et per hoc dicit Dionysius, quod licet viventia sint nobiliora quam existentia, tamen esse est nobilius quam vivere : viventia enim non tantum habent vitam, sed cum vita simul habent et esse». La referencia implícita concierne a Pseudo-Denys l'Aréopagite, Les noms divins V, § 3, I. 1-19, 817 A-C.

${ }^{59}$ In De div. nom., cap. V, lect. 1 (éd. Marietti, $n^{\circ}$ 639): «Et si ista quae sunt principia aliorum, non sunt nisi per participationem essendi, multo magis ea quae participant ipsis, non sunt nisi per participationem ipsius esse. Et sic patet quod Deus per ipsum esse omnia causat». 
acto en la $\cos ^{60}$. De esta manera, como substancialmente lo señalaba Dominique Dubarle, la constitución del ens es a la vez la participación formal -más formal que la forma misma- del esse y el efecto propio del obrar divino ${ }^{61}$.

Esta doble valencia del esse participado nos permite comprender fácilmente la procesión del bien a partir del ente. Poniendo una substancia creada frente al creador, la creación la constituye, ante todo, como un sujeto que posee en sí mismo el esse especificado por la esencia que el mismo esse actúa, con aquellos accidentes que son requeridos para su consistencia mínima; en este estadio ontológico, este sujeto es, como lo hemos visto, un ens simpliciter que, sin embargo, sólo es un bonum secundum quid, porque no ha alcanzado el grado de perfección actual al cual tiende en razón de su naturaleza. Por esto el gobierno divino, precisamente gracias a la mediación este esse substancial, va a conducir a este mismo sujeto a la perfección última del cual es capaz por medio de las formas accidentales complementarias y -si es viviente- de las operaciones vitales aptas para completarlo; en este estadio, el sujeto añade a su ser substancial una configuración que resulta ens secundum quid y lo vuelve bonum simpliciter. ¿Se desea la ayuda de un ejemplo? Diremos entonces que, inmediatamente que ha salido de su cascarón y es viable, el herrerillo es un ens, en el sentido de que su esencia (obviamente individual) recibe y posee el acto de ser que ella misma mide; pero es claro que, durante sus primeros días de vida, el herrerillo sólo ejerce sus facultades vitales de modo imperfecto, que sólo tiene -en relación a las virtualidades de su propia naturaleza- una bondad relativa. Cuando habrá llegado a ser adulto, en cambio, gozará de todas las riquezas de su esencia, y podrá así nutrirse a sí mismo, reproducirse, volar y chillar; en ese momento, el conjunto de los grados de actualidad relativa añadidos a su ser substancial le conferirán la bondad perfecta -simpliciter- a la cual tiende su naturaleza. Lo que

\footnotetext{
${ }^{60}$ Sobre la mediación trascendental del esse, cf. C. Fabro, Participation et causalité selon S. Thomas d'Aquin..., p. 363-380.

${ }^{61}$ Cf. Dominique Dubarle, L'ontologie de Thomas d'Aquin, «Philosophie et théologie», Paris, Cerf, 1996, p. 202-212. Entre los numerosos lugares tomasianos, citamos Sum. theol., $I^{a}$, q. 8, q. 1, c.: «Cum autem Deus sit ipsum esse per suam esentiam, oportet quod esse creatum sit proprius effectus eius; sicut ignire est proprius effectus ignis. Hunc autem effectum causat Deus in rebus, non solum quando primo esse incipiunt, sed quandiu in esse conservantur; sicut lumen causatur in aere a sole quandiu aer illuminatus manet».
} 
cambia entre el primer y el segundo estado no es su esse, que permanece siempre el mismo -fixum et quietum in ente, señala santo Tomás ${ }^{62}$ - sino la amplitud de su participación total de la virtus essendi de este esse.

\section{Conclusión}

Dos tesis de fondo se despejan de nuestra breve radiografía del Super Dionysii De divinis nominibus: una es la fundación del bien en el esse, que invierte la jerarquía de prioridades propuesta por el Pseudo Dionisio, y la otra es esto que podríamos llamar la intensificación del esse, promovido a la dignidad de acto primero y último del ente, a partir y más allá del mismo Pseudo Dionisio. La segunda de estas tesis esconde una paradoja de primera importancia para la inteligencia de la metafísica tomasiana. Por un lado, el acto de ser, siendo «más anciano» que todas las otras perfecciones, es, a través de la participación, el principio radical que las precontiene y más allá del cual es imposible, dentro de la cosa, elevarse. Pero, por otra parte, al mismo tiempo la creatura sólo alcanza su bondad última gracias a las perfecciones accidentales y operativas sobreañadidas a su esse, como lo enseña muy claramente un pasaje de la Expositio libri Boetii De ebdomadibus:

...en los bienes creados hay una doble bondad, una según que se dicen buenos por relación al primer bien $-\mathrm{y}$, según esto, también su ser y lo que hay en ellos por el primer bien es bueno-; otra bondad, en cambio, es considerada absolutamente en ellos, es decir, según que cada uno se dice bueno en cuanto es perfecto en el ser y en el obrar, y esta perfección no compete a los bienes creados según su mismo ser esencial, sino según algo sobreañadido que se llama su virtud, como se dijo antes ${ }^{63}$.

\footnotetext{
${ }^{62}$ Cf. S. Thomas, Contra Gent., Lib. I, cap. 20 (éd. Éd. Marietti, n 179): «Esse autem est aliquid fixum et quietum in ente».

${ }^{63} \mathrm{~S}$. Thomas, Expositio libri Boetii De ebdomadibus, lect. 4, in fine: «...in bonis creatis est duplex bonitas, una quidem secundum quod dicuntur bona per relationem ad primum bonum, et secundum hoc et esse eorum et quicquid in eis est a primo bono est bonum; alia uero bonitas consideratur in eis absolute, prout scilicet unumquodque dicitur bonum in quantum est perfectum in esse et in operari, et hec quidem perfectio non competit bonis creatis secundum ipsum esse essenciale eorum, sed secundum aliquid superadditum quod dicitur uirtus eorum ut supra dictum est». Según J.-P. Torrell, Initiation à saint Thomas d'Aquin..., p. 460, «la date de cet ouvrage est sans doute postérieure à celle de l'autre Commentaire sur Boèce (De Trinitate), mais il n'est guère possible de préciser davantage la date ni les circonstances. Gauthier (Léon., t. 25/2, p. 498) propose avec quelque doute: Paris, 1271-72». Si esta datación hipotética fuera verdadera, el texto que acabamos de citar sería, pues, posterior al Super librum Dionysii De divinis nominibus.
} 
Hay una bondad primera incluida en el don del esse y de su determinación por la esencia, y, luego, hay una bondad absoluta que resulta de los accidentes perfectivos $y$, entonces, se agrega al mismo ser. Mientras que la bondad integral de la cosa parecía comprendida en la actualidad de su esse, ahora parece exterior a él. Para desatar esta aporía, podemos apoyarnos en la comparación entre las dos tríadas esse-vivere-intelligere y ens-vivens-intelligens que santo Tomás elabora a partir del capítulo $\mathrm{V}$ de Los nombres divinos. Leemos en la $I^{a}-I^{a e}$.

El ser, tomado absolutamente (simpliciter), en cuanto que incluye en sí toda la perfección de ser, tiene preeminencia sobre la vida y sobre todo lo subsecuente; en efecto, así el mismo ser precontiene en sí todas las [perfecciones] subsecuentes. Y así habla Dionisio. Pero, si se considera el mismo ser en cuanto es participado (esse prout participatur) en esta o aquella cosa, que no abarcan toda la perfección de ser, sino que tienen un ser imperfecto -como es el ser de cualquier creatura-, así es claro que el mismo ser con cierta perfección añadida es más eminente. De donde también Dionisio, en el mismo lugar, dice que los vivientes son mejores que los existentes, y los inteligentes, que los vivientes ${ }^{64}$.

El esse del ente debe ser considerado de dos maneras: en su propia naturaleza de ser, en tanto que esse, por un lado; luego, en tanto que participado por el ente que es actuado por él, limitado por la contracción que le asigna la esencia (creada), por otro lado. Bajo el primer respecto, el acto de ser «precontiene» (praehabet) -en latín clásico, se podría escribir «suministra ${ }^{\mathrm{XIII}}$ 》 (praehibit)- las perfecciones puras de las cuales es aquí la cuestión, pero también, más ampliamente, todas las características predicamentales susceptibles de volverse concretas en las cosas. Bajo el segundo respecto, en cambio, el esse no es más tomado en sí mismo en toda su virtus essendi, sino solamente según que una cierta «parte» es comunicado a este

\footnotetext{
${ }^{64}$ Sum. theol., $I^{a}-1 I^{a e}$, q. 2, a. 5, ad 2: "esse simpliciter acceptum, secundum quod includit in se omnem perfectionem essendi, praeeminet vitae et omnibus subsequentibus : sic enim ipsum esse praehabet in se omnia subsequentia. Et hoc modo Dionysius loquitur. - Sed, si consideretur ipsum esse prout participatur in hac re vel in illa, quae non capiunt totam perfectionem essendi, sed habent esse imperfectum, sicut est esse cuiuslibet creaturae ; sic manifestum est quod ipsum esse cum perfectione superaddita est eminentius. Unde et Dionysius ibidem dicit quod viventia sunt meliora existentibus, et intelligentia viventibus». La misma dualidad de consideraciones sobre el esse y el ens, a partir del Pseudo Dionisio, se halla en Sum. theol., $1^{a}$, q. 4, a. 2, ad 3.

XIII El autor usa la locución francesa «fournit» que mejor queda traducida por «forne», pero, siendo tan poco usual el verbo fornir, resulta un tanto oscuro como traducción.
} 
ente, con exclusión de lo que -por así decir- puede ser recibido en otros entes ${ }^{65}$. Pero es necesario diferenciar ulteriormente, más allá de la letra del texto citado, este esse participado: podemos, en efecto, considerarlo según que es distinto del ente al cual él da el ser, o bien -de manera opuesta- según que entra en composición con la esencia de este ente ${ }^{66}$. En el primer caso, tratamos con el ser en tanto que acto (esse ut actus) del ente, que ciertamente es el acto de esta substancia, pero que, sin embargo, miramos en sí mismo: se trata, entonces, del esse-principio, que hace que el ente $-y$ todo lo que contiene el ente- sea, pero que en sí mismo no es. Retomando nuestro ejemplo, diremos que este esse es el acto que da el ser al herrerillo y, luego, a todos sus accidentes, pero que, en sí mismo, no es. Él es medido por la naturaleza de este pájaro, y por esto no se tratará del ser de un petirrojo; pero también trasciende, sin embargo, de alguna manera la esencia substancial que lo recibe, y por esto se expande más allá de ella en las propiedades y las operaciones específicas del herrerillo. En el segundo caso, al contrario, estamos en presencia de un cierto ser en acto (esse in $a c t u$ ), que será ante todo aquel de esta substancia en acto en el universo y delante de mi inteligencia, $y$, luego, por «adiciones» sucesivas, el de las formas

65 Sobre este punto, cf. F. O'Rourke, Pseudo-Dionysius and the Metaphysics of Aquinas..., p. 183: "Considered simply or absolutely in itself, as including all the perfection of existing, esse surpasses life and all subsequent perfections; in this sense being contains in itself all such secondary perfections which it transcends while embracing them. This, says Aquinas, is the meaning intended by Dionysius. The objection posed presumes the alternative understanding of being, namely esse as participated in this or that thing has esse in an imperfect manner, as is the minimum measure of being in any creature; in this case it is clear that being itself (ipsum esse) with an additional perfection is more excellent. Because of this Dionysius can also say that living things are better than existing things and intelligent beings than living things». Ver también Id., "Virtus essendi: Intensive Being in PseudoDionysius and Aquinas», Dionysius 15 (1991), p. 31-80, en particular p. 75-76. Si el autor ha comprendido bien una valencia del texto citado $\left(I^{a}-I I^{a e}\right.$, q. 2, a. 5, ad 2$)$, que completa el análisis que proponemos, nos parece, sin embargo, muy importante no recurrir al léxico de la existencia para traducir el esse tomasiano, precisamente porque el primer analogado de este es el esse intensivo, en el cual se enraízan tanto las perfecciones formales de la cosa como su existencia. Apoyándose en el mismo lugar de la $I^{a}-I I^{a e}, C$. Fabro remarca de su parte en Participation et causalité selon S. Thomas d'Aquin..., p. 217-218: «Dans l'ordre formel, selon "I'échelle" aristotélicienne des êtres, l'intellectualité occupe le sommet, et Aristote a excellement appelé Dieu la Pensée pure, et les créatures sont d'autant plus parfaites et plus proches de Dieu que leur intellectualité est la plus haute [...]. Mais dans l'ordre réel -l'ordre de l'acte- s'achève le renversement du passage à la limite et l'esse devient le complexe de toutes les perfections et dépasse tout, selon la version dionysienne de la dialectique platonicienne; c'est en ce passage à la limite que sont dominés platonisme et aristotélisme».

${ }^{66}$ La distinción que proponemos aquí se apoya en S. Thomas, De spiritualibus creaturis, a. 1, c.: «Et cum quaelibet res participet per assimilationem primum actum in quantum habet esse, necesse est quod esse participatum in unoquoque comparetur ad naturam participantem ipsum sicut actus ad potentiam». Emerge claramente que: $1^{\circ}$ el esse del cual se trata aquí es el esse ut actus; $2^{\circ}$ delante de él, la naturaleza (o esencia) es, en sí misma, potentia; $3^{\circ}$ la misma naturaleza, en tanto que actuada por el esse ut actus, adquiere su esse in actu. 
accidentales en acto en la substancia en cuestión, y, por último, el de las operaciones que provienen de estas formas: se trata ahora del esse-resultado, es decir, del ente -substancial o accidental- que es en acto, pero que no es su acto. Para nuestro herrerillo, este ser en acto es aquel de su esencia substancial, al cual se añaden -principalmente- el de todas sus facultades vitales y sensitivas, y el de sus actividades, por ejemplo, de su canto.

La solución de nuestro problema se halla en esta distinción entre los dos sentidos del esse participado en el ente. Así como el esse ut actus del suppositum viviente o intelectivo contiene virtualmente las perfecciones puras de la vida y de la sabiduría, así también está al principio de la bondad primera $\mathrm{y}$, después, por la intermediación de la esencia substancial en acto, de la bondad segunda del ente del cual él es el acto originario. Pero, inversamente, así como es necesario añadir el ser accidental de las facultades y de las operaciones vitales o intelectuales al esse in actu de la substancia para que ella ejerza efectivamente las operaciones de la vida o de la sabiduría, así también este ser participado sólo confiere al ente su bondad relativa primera, de tal suerte que la cosa sólo llega a su bondad perfecta mediante «la adición» de una configuración de perfecciones segundas proporcionada a su naturaleza. El Doctor angélico se expresa de manera muy clara acerca de este punto en la conclusión de una respuesta a una objeción de la cual ya hemos citado antes el inicio:

Así pues, según el primer ser, que es substancial, se dice que algo es ente absolutamente y bueno relativamente, esto es, en cuanto es ente; en cambio, según el acto último, se dice que algo es ente relativamente y bueno absolutamente. Así pues, lo que dice Boecio -que, en las cosas, ser bueno es distinto de ser- hay que referirlo al ser bueno y al ser absolutamente, porque, según el primer acto, algo es ente simplemente, $y$, según el último, bueno simplemente. $Y$, sin embargo, según el primer acto, es de algún modo bueno, y, según el último acto, es de algún modo ente $^{67}$.

67 Sum. theol., $1^{a}$, q. 5, a. 1, ad 1: «Sic ergo secundum primum esse, quod est substantiale, dicitur aliquid ens simpliciter et bonum secundum quid, idest inquantum est ens: secundum vero ultimum actum, dicitur aliquid ens secundum quid, et bonum simpliciter. Sic ergo quod dicit Boetius, quod in rebus aliud est quod sunt bona, et aliud quod sunt, referendum est ad esse bonum et ad esse simpliciter: quia secundum primum actum est aliquid ens simpliciter; et secundum ultimum, bonum simpliciter. Et tamen secundum primum actum est quodammodo bonum: et secundum ultimum actum est quodammodo ens». 
La bondad absoluta del ente creado se obtiene, pues, por la integración de varios grados de actualidad, de los cuales santo Tomás menciona el primero y el último, es decir, el del ser substancial y el de la perfección última. Desde este punto de vista -que es el del ser en acto (esse in actu)-, se trata de añadir al ens simpliciter de la substancia el ens secundum quid para que ella alcance el máximo de bondad del cual es capaz. Pero, si el ente «tomado absolutamente» es la substancia real en acto, lo es porque ella es «lo que tiene ser» ${ }^{68}$. Por esto, se impone un segundo punto de vista, aquel del ser en tanto que acto (esse ut actus). Considerado, en esta perspectiva, a partir de su principio, el ente creado sólo deviene bueno absolutamente por «adiciones» a la síntesis de esse y esencia que lo erige como suppositum; pero los añadidos así requeridos para acceder a su fin último son también participaciones, en cascada, de su acto de ser. La primera additio es la contracción del acto de ser originario por la esencia substancial; de esto resulta el ens simpliciter, que participa del esse según la capacidad receptiva de la essentia. La segunda additio concierne a los accidentes propios, que participan, por un lado, del ser en acto del ens simpliciter -es decir, de la substancia en tanto que ella es el principio activo de ellos- pero, por otro lado, se añaden a ella en tanto que es el sujeto receptor ${ }^{69}$. Cuando el ente es viviente, una tercera additio permite que las operaciones perfectivas emanen de las potencias vitales correspondientes de manera análoga: por participación, en tanto que estas facultades son sus principios activos, y por actuación, en tanto que ellas son sus sujetos.

\footnotetext{
${ }^{68}$ Cf. S. Thomas, In Metaph., Lib. XI, lect. 3 (Marietti, n 2197): «Nam ens simpliciter, dicitur id quod in se habet esse, scilicet substantia. Alia vero dicuntur entia, quia sunt huius quod per se est, vel passio, vel habitus, vel aliquid huiusmodi»; Sum. theol., $I^{a}-I^{a e}$, q. 26, a. 4, c.: «...ens simpliciter est quod habet esse, ens autem secundum quid quod est in alio».

${ }^{69}$ Cf. Sum. theol., $I^{a}$, q. 77, a. 6, c.: «...actualitas per prius invenitur in subiecto formae accidentalis, quam in forma accidentali: unde actualitas formae accidentalis causatur ab actualitate subiecti. Ita quod subiectum, inquantum est in potentia, est suceptivum formae accidentalis: inquantum autem est in actu, est eius productivum. Et hoc dico de proprio et per se accidente: nam respectu accidentis extranei, subiectum est susceptivum tantum; productivum vero talis accidentis est agens extrinsecum». El sujeto en acto, gracias a la forma substancial actuada por el acto de ser, actúa a su vez a las propiedades accidentales: he aquí las participaciones que, por así decir, descienden del esse; pero el mismo sujeto substancial es también en potencia a las mismas formas accidentales: he aquí las «adiciones» que vienen a perfeccionar al ens simpliciter gracias al ens secundum quid.
} 
Participación y «adición»: estas dos nociones nos revelan la clave de nuestro problema. Por la adición al esse ut actus de la esencia que lo recibe y lo determina como la potencia determina al acto $^{70}$, y simultáneamente por participación de la esencia así actuada del esse que la actúa, el sujeto substancial es constituido en su bondad primera, que sólo es relativa (secundum quid) en atención de las exigencias de su naturaleza. Solamente por la adición ulterior a este esse in actu substancial de los accidentes y de las operaciones que le son debidas, y simultáneamente por participación de éstos del esse ut actus mediatizado por la forma substancial, el sujeto en cuestión accede a su bondad absoluta (simpliciter). En razón de la additio, los grados de bondad son distintos entre ellos tanto como delante del acto de ser, y esto de manera real, antes de toda consideración del espíritu; el ente tomasiano no es una mónada leibniziana en cuya definición las propiedades estarían ya plenamente contenidas. Pero, al mismo tiempo, a causa de la participación, los grados de bondad se derivan, por etapas, del esse ut actus, de manera acumulativa; por esto, el ens teorizado por el Doctor angélico no es en absoluto un ser malebranchiano que permanecería en sí mismo extraño a una perfección operativa, la cual le sería conferida por Dios desde fuera. Incluida en la virtus essendi del acto de ser, la doble bondad del ente le es intrínseca porque es «lo que es»; pero como este esse es el mediador, por participación, de la causalidad divina, ella está asimismo completamente fundada en la plenitud del Ipsum esse subsistens y en su generosidad. Todo este proceso del bien a partir del esse concretiza una característica del acto: «Pertenece a la naturaleza de cualquier acto comunicarse cuanto le es posible» ${ }^{71}$.

Para terminar, nos parece útil visualizar en un cuadro sintético las relaciones entre el ser y el bien que el presente estudio ha puesto en evidencia:

\footnotetext{
${ }^{70}$ Recordamos aquí que la determinación del esse por la esencia de ningún modo es una actuación, sino antes bien -si dicere licet- una «potencialización». Cf. S. Thomas, Q. De potentia, q. 7, a. 2, ad 9: «...non sic determinatur esse per aliud sicut potentia per actum, sed magis sicut actus per potentiam».

${ }^{71}$ S. Thomas, Q. De potentia, q. 2, a. 1, c. (agregamos el contexto): «Natura cuiuslibet actus est, quod seipsum communicet quantum possibile est. Unde unumquodque agens agit secundum quod in actu est. Agere vero nihil aliud est quam communicare illud per quod agens est actu, secundum quod est possibile». Siendo el esse la actualidad de todos los actos, tiende necesariamente a difundirse en el ente, proporcionalmente a la apertura de la esencia que lo especifica.
} 


\begin{tabular}{|c|c|c|c|}
\hline & esse & participación & bondad \\
\hline Dios & $\begin{array}{l}\text { Ipsum esse } \\
\text { subsistens }\end{array}$ & $\begin{array}{l}\text { no participante; participado trascendente } \\
\text { y separado de todos sus participantes }\end{array}$ & $\begin{array}{l}\text { bondad subsistente } \\
\text { por esencia }\end{array}$ \\
\hline \multirow{4}{*}{ creatura } & $\begin{array}{l}\text { esse ut actus } \\
\text { creado }\end{array}$ & $\begin{array}{l}\text { participante del Ipsum esse subsistens; } \\
\text { participado directamente por la } \\
\text { substancia, e indirectamente por los } \\
\text { accidentes }\end{array}$ & $\begin{array}{l}\text { principio radical de } \\
\text { toda la bondad del } \\
\text { ente }\end{array}$ \\
\hline & $\begin{array}{l}\text { esse in actu de la } \\
\text { substancia }\end{array}$ & participante directamente del esse ut actus & $\begin{array}{l}\text { vuelve al suppositum } \\
\text { bonum secundum quid }\end{array}$ \\
\hline & $\begin{array}{l}\text { esse in actu de } \\
\text { las potencias } \\
\text { operativas }\end{array}$ & $\begin{array}{l}\text { participante del esse ut actus a través de la } \\
\text { substancia }\end{array}$ & $\begin{array}{l}\text { completa la bondad } \\
\text { substancial }\end{array}$ \\
\hline & $\begin{array}{l}\text { esse in actu de } \\
\text { las operaciones }\end{array}$ & $\begin{array}{l}\text { participante del esse ut actus a través de la } \\
\text { substancia y de las potencias; término del } \\
\text { proceso de participación }\end{array}$ & $\begin{array}{l}\text { vuelve al suppositum } \\
\text { bonum simpliciter }\end{array}$ \\
\hline
\end{tabular}

Resulta así que el Aquinate va de acuerdo con el Pseudo Dionisio en tres grandes tesis, solidarias entre ellas:

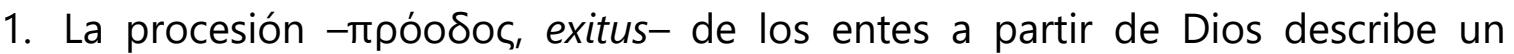

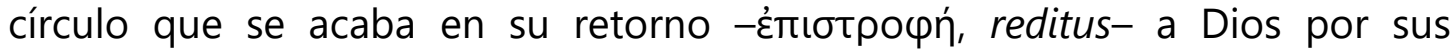
operaciones perfectivas.

2. El motivo de la procesión y del retorno reside en la bondad divina, a la cual pertenece comunicar libremente algo de su plenitud incomunicable.

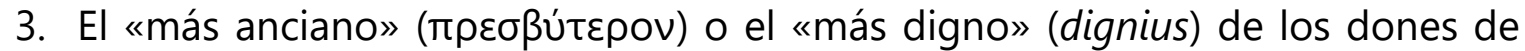
Dios es el ser ( $\varepsilon \hat{i v} \alpha \mathrm{l}$, esse), que mediatiza la causalidad del creador sobre la creación.

En cambio, Tomás contradice a Dionisio en tres tesis que exceden a las anteriores:

1. El círculo del exitus-reditus, gracias al cual los entes pasan de su bondad primera a su bondad última, se origina en el Ser subsistente de Dios y se acaba, por participación, en él.

2. El fundamento de la procesión y del retorno se halla en el Ipsum esse subsistens.

3. El esse no es solamente el primero de los dones de Dios, es también y sobre todo el primero de sus nombres ${ }^{\mathrm{XIV}}$.

XIV Traducción de Diego José Bacigalupe. 